\title{
Retraction
}

\section{Retracted: Inhibition Effect of Substituted Thiadiazoles on Corrosion Activity of N80 Steel in HCl Solution}

\author{
Journal of Metallurgy \\ Received 13 November 2018; Accepted 13 November 2018; Published 10 March 2019 \\ Copyright (c) 2019 Journal of Metallurgy. This is an open access article distributed under the Creative Commons Attribution License, \\ which permits unrestricted use, distribution, and reproduction in any medium, provided the original work is properly cited.
}

Journal of Metallurgy has retracted the article titled "Inhibition Effect of Substituted Thiadiazoles on Corrosion Activity of N80 Steel in $\mathrm{HCl}$ Solution" [1]. The article was found to contain images reused in several other articles published by Mahendra Yadav and colleagues. The details of the reuse of images are as follows:

Figure 9(b) is similar to Figure 11b in [2], Figure 17b in [3], Figure 14b in [4], and Figure 5b in [5]. Figure 9(c) is similar to Figure 11c in [2], Figure 17c in [3], and Figure 14c in [4]. In particular, Figure 9 in [1] shares the same image of a sample in $\mathrm{HCl}$ as Figure 11 in [2] and the same image in the presence of an inhibitor, but these represent different inhibitors in each article, AMPT, and BAL, respectively.

We asked the authors to provide the underlying uncropped and unadjusted scanning electron microscopy (SEM) images, the raw data, and details of how the experiments were conducted.

The corresponding author, Dr. Yadav, said the SEM work was outsourced but did not give details on where, when, or by whom this work was performed. The equipment is described as a "JEOL JSM-6380 LA analytical scanning electron microscope" in this article. However, there is no description of the scanning electron microscope in [2] and in [6] it is described as a "Scanning Electron Microscope model SEM Jeol JSM-5800." These are not the same model of microscope, despite these articles sharing some of the same SEM images.

Dr. Yadav provided us with replacement figures. However, they were identical for two of the articles, [1, 6], despite representing experiments with the inhibitors AMPT and ODAEODI, respectively. We were not told how these images were generated, the images were of low resolution, and the text in the images was illegible.

The corresponding author agreed to retraction and we have asked the institution to formally investigate.

\section{References}

[1] M. Yadav, S. Kumar, and D. Behera, "Inhibition Effect of Substituted Thiadiazoles on Corrosion Activity of N80 Steel in $\mathrm{HCl}$ Solution," Journal of Metallurgy, vol. 2013, Article ID 256403, 14 pages, 2013.

[2] M. Yadav, S. Kumar, and P. N. Yadav, "Corrosion Inhibition of Tubing Steel during Acidization of Oil and Gas Wells," Journal of Petroleum Engineering, vol. 2013, Article ID 354630, 9 pages, 2013.

[3] M. Yadav, U. Sharma, and P. N. Yadav, "Isatin compounds as corrosion inhibitors for N80 steel in 15\% HCl," Egyptian Journal of Petroleum, vol. 22, no. 3, pp. 335-344, 2013.

[4] M. Yadav, U. Sharma, and P. Yadav, "Corrosion inhibitive properties of some new isatin derivatives on corrosion of N80 steel in 15\% $\mathrm{HCl}$," International Journal of Industrial Chemistry, vol. 4, no. 1, p. 6, 2013.

[5] M. Yadav, P. N. Yadav, and U. Sharma, "Substituted imidazoles as corrosion inhibitors for N80 steel in hydrochloric acid," Indian Journal of Chemical Technology, vol. 20, pp. 363-370, 2013.

[6] M. Yadav, S. Kumar, U. Sharma, and P. N. Yadav, "Substituted amines as corrosion inhibitors for $\mathrm{N} 80$ steel in $15 \% \mathrm{HCl}$," Journal of Materials and Environmental Science, vol. 4, no. 5, pp. 691700, 2013. 


\title{
Inhibition Effect of Substituted Thiadiazoles on Corrosion Activity of N80 Steel in HCl Solution
}

\author{
M. Yadav, Sumit Kumar, and Debasis Behera \\ Department of Applied Chemistry, Indian School of Mines, Dhanbad 826004, India
}

Correspondence should be addressed to M. Yadav; yadav_drmahendra@yahoo.co.in

Received 29 November 2012; Revised 2 March 2013; Accepted 18 March 2013

Academic Editor: Elena V. Pereloma

Copyright (C) 2013 M. Yadav et al. This is an open access article distributed under the Creative Commons Attribution License, which permits unrestricted use, distribution, and reproduction in any medium, provided the original work is properly cited.

\begin{abstract}
The inhibition effect of some prepared compounds, namely, thiadiazole derivatives, on N80 steel corrosion in $15 \% \mathrm{HCl}$ solutions has been studied by using the weight loss, electrochemical polarization, and electrochemical impedance spectroscopy techniques. It was found that the inhibition efficiency of the thiadiazole derivatives, namely, 2-amino-5-(4-methoxyphenyl)-1,3,4-thiazole (AMPT), 2-amino-5-phenyl-1,3,4-thiazole (APT), and 2-amino-5-(4-chlorophenyl)-1,3,4-thiazole (ACPT), increases with the increase in concentration. Inhibition efficiency follows the order AMPT $>$ APT $>$ ACPT. The effect of temperature on the corrosion was investigated by the weight loss method, and some thermodynamic parameters were calculated. The inhibitive action may be attributed to the adsorption of inhibitor molecules on the active sites of the metal surface following Langmuir adsorption isotherm. Polarization measurements indicated that thiadiazole derivatives act as mixed-type corrosion inhibitor. The adsorption of thiadiazole derivatives on N80 surface exposed to inhibitor-containing solutions was confirmed using SEM and FT-IR spectra.
\end{abstract}

\section{Introduction}

N80 carbon steel has been generally used as the main construction material for down hole tubular, flow lines, and transmission pipelines in petroleum industry. In most industrial processes, acidic solutions are commonly used for pickling, industrial acid cleaning, acid descaling, oil well acidifying, and so forth [1-5]. It is commonly noticed that $15-28 \%$ of hydrochloric acid is used for the acidization of petroleum oil wells [6, 7]. Because of their aggressiveness, iron and its alloys get corrodes during these acidic applications particularly with the use of hydrochloric acid and sulphuric acid, which results in terrible waste of both resources and money [8]. Addition of inhibitor remains the necessary procedure to secure the metal against acid attack. Therefore, corrosion inhibitors for $\mathrm{HCl}$ solutions have attracted more attention. Most of the well-known corrosion inhibitors are organic compounds containing polar groups having nitrogen, sulphur, and/or oxygen atoms and heterocyclic compounds with polar functional groups and conjugated double bonds $[9,10]$. These compounds can adsorb on the metal surface and partially blocking the active sites on the surface, thereby reducing the corrosion rate. Among different nitrogen- and sulphur-containing compounds, thiosemicarbazide has been reported to be a potential inhibitor for different metals [11, 12]. Most of the investigation is related to the application of common inhibitors like various derivatives of the compound of aminothiazoles [13], benzotriazoles [14-16], thioimidazole [17], mercapto-5-triazole [18], and thiadiazole [19, 20] which have been used as potential inhibitors for this system.

Keeping in the view of the above excellent behavior of the organic compounds containing nitrogen and sulphur as corrosion inhibitors, some compounds of substituted thiadiazoles, namely, 2-amino-5-(4-methoxyphenyl)-1, 3,4-thiadiazole (AMPT), 2-amino-5-phenyl-1,3,4-thiadiazole (APT), and 2-amino-5-(4-chlorophenyl)-1,3,4-thiadiazole (ACPT), have been synthesized, and their corrosion inhibition property was studied by the weight loss technique and electrochemical techniques.

\section{Experimental Section}

\subsection{Materials}

2.1.1. Composition of N80 Sample. The working electrode and specimens for weight loss experiments were prepared from oil 
well N80 steel having the percentage composition (wt.\%) as shown in Table 1 . The specimens were mechanically abraded with $320,400,600,800,1000$, and 1200 emery paper, washed in acetone and double-distilled water, then dried, and put into the cell.

2.1.2. Solutions. The aggressive solutions were made up of $37 \% \mathrm{HCl}$ (Rankem). The concentration of the used inhibitors ranged from $20 \mathrm{ppm}$ to $200 \mathrm{ppm}$ in $15 \% \mathrm{HCl}$. All solutions were prepared in double-distilled water.

2.1.3. Synthesis of Corrosion Inhibitor. The inhibitors AMPT, APT, and ACPT were synthesized in the laboratory by a reported method [21] as shown in Scheme 1. An equimolar mixture of substituted benzoic acid $(0.05 \mathrm{~mol})$, thiosemicarbazide $(0.05 \mathrm{~mol})$, and phosphorous oxychloride $(15 \mathrm{~mL})$ was refluxed gently for half an hour. After cooling, water was added $(45 \mathrm{~mL})$ and the mixture was refluxed for $4 \mathrm{~h}$ and filtered. The solution was neutralized with saturated solution of potassium hydroxide. The precipitate was filtered and recrystallized from ethanol. Their purity was confirmed by TLC. The structure of inhibitors is shown in Table 2.

\subsection{Methods}

2.2.1. Weight Loss Method. The N80 specimens were cut in the dimension of $3 \mathrm{~cm} \times 3 \mathrm{~cm} \times 0.1 \mathrm{~cm}$ with a small hole of $2 \mathrm{~mm}$ at the upper edge of specimen for weight loss studies, and the size of the electrodes was $1 \mathrm{~cm} \times 1 \mathrm{~cm}$ with $4 \mathrm{~cm}$ long tag for electrochemical studies with an exposed area of $1 \mathrm{~cm}^{2}$ towards aggressive solution. The specimens were mechanically abraded successively with $1 / 0,2 / 0,3 / 0$, and $4 / 0$ grade emery papers. The surface was thoroughly washed with soap, running tap water, and distilled water and finally was degreased with acetone. The samples were dried and stored in vacuum desiccators before immersion in the test solution. Weight loss measurements were performed at $303 \mathrm{~K}$ for $6 \mathrm{~h}$ by immersing the $\mathrm{N} 80$ steel coupons into $250 \mathrm{~mL}$ of $15 \%$ hydrochloric acid in the absence and the presence of various amounts of inhibitors. After the elapsed time, the specimens were taken out, washed, dried, and weighed accurately. The experimental studies were performed at temperature range of $303 \mathrm{~K}$ to $333 \mathrm{~K}$. The inhibition efficiency (IE\%) and surface coverage $(\theta)$ were determined by using following equation [22]:

$$
\mathrm{CR}(\mathrm{mmpy})=\frac{87.6 \Delta W}{D A T}
$$

where $\Delta W=$ weight loss $(\mathrm{mg}), D=$ density of specimen $\left(\mathrm{g} / \mathrm{cm}^{3}\right), A=$ area of specimen $\left(\mathrm{cm}^{2}\right)$, and $T=$ exposure time (hours). The degree of surface coverage $(\theta)$ by inhibitors can be expressed in terms of corrosion rate as

$$
\begin{gathered}
\theta=\frac{\mathrm{CR}_{0}-\mathrm{CR}_{\mathrm{inh}}}{\mathrm{CR}_{0}}, \\
\mathrm{IE} \%=\frac{\mathrm{CR}_{0}-\mathrm{CR}_{\mathrm{inh}}}{\mathrm{CR}_{0}} \times 100,
\end{gathered}
$$

TABLE 1: Composition of specimens.

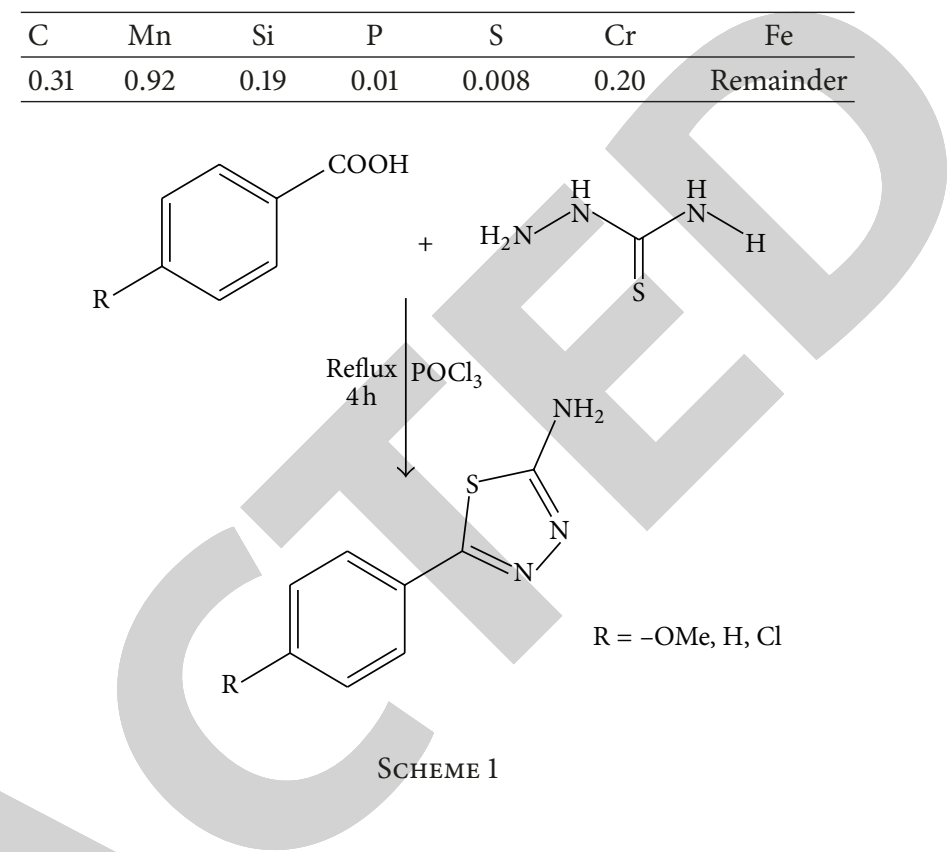

where $\mathrm{CR}_{0}=$ corrosion rate in the absence of inhibitor and $\mathrm{CR}_{\mathrm{inh}}=$ corrosion rate in the presence of inhibitor.

2.2.2. Electrochemical Method. The electrochemical experiments were carried out in a three-necked glass assembly containing $250 \mathrm{~mL}$ of the electrolyte with different concentrations of inhibitors (from $20 \mathrm{ppm}$ to $200 \mathrm{ppm}$ by weight) dissolved in it. The electrochemical studies were carried out with N80 steel strips having an exposed area of $1 \mathrm{~cm}^{2}$. The rest of the samples were isolated from the working environment by a cold mounting process, for which epoxy resin had been used. A conventional three-electrode cell consisting of N80 steel as a working electrode, platinum as counter electrode, and a saturated calomel electrode as reference electrode was used. Polarisation studies were carried out using an AMEL Potentiostat 2053, Italy, connected to a personal computer. Prior to electrochemical measurements, the working electrode was first immersed into the test solution for $30 \mathrm{~min}$ to establish a steady-state open circuit potential. After the establishment of the open circuit potential, dynamic polarization curves were obtained with a scan rate of $1 \mathrm{mV} / \mathrm{s}$ in the potential range from -470 to $-390 \mathrm{mV}$ with scan rate of $10 \mathrm{~m} \mathrm{Vs}^{-1}$. All potentials were measured against SCE. All experiments were performed at $30 \pm 0.2^{\circ} \mathrm{C}$ in an electronically controlled air thermostat. The inhibition efficiency (IE \%) was calculated using the following equation:

$$
\% \mathrm{IE}=\left[\frac{\left(I_{0}-I_{\mathrm{inh}}\right)}{I_{0}}\right] \times 100,
$$

where $I_{0}=$ corrosion current in the absence of inhibitor and $I_{\text {ihn }}=$ corrosion current in the presence of inhibitor.

AC-impedance studies were carried out in threeelectrode cell assembly containing N80 steel as the working electrode, platinum as counter electrode, and saturated calomel as reference electrode. The impedance measurements 
TABLE 2: Name and structural formulae of compounds thiadiazole derivatives.

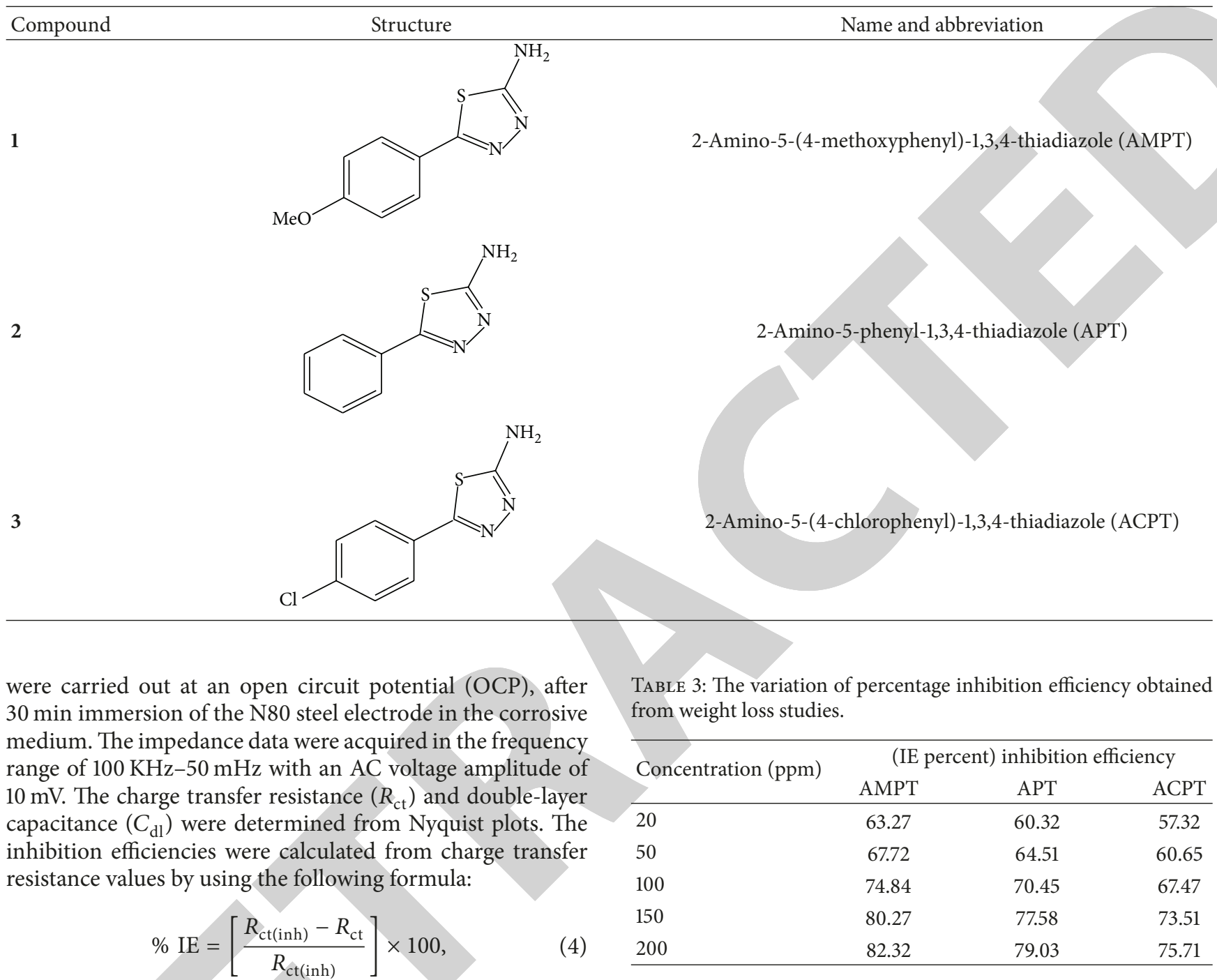

where $R_{\mathrm{ct}}=$ charge transfer resistance in absence of inhibitor; $R_{\mathrm{ct}(\mathrm{Inh})}=$ charge transfer resistance in presence of inhibitor.

2.2.3. Scanning Electron Microscopic (SEM) Analysis. The $\mathrm{N} 80$ specimens of size $1.0 \mathrm{~cm} \times 1.0 \mathrm{~cm} \times 0.06 \mathrm{~cm}$ were abraded with a series of emery papers (grades 320, 500, 800, and 1200) and then washed with distilled water and acetone. After immersion in $15 \% \mathrm{HCl}$ in the absence and the presence of optimum concentration of inhibitor (AMPT) at $30^{\circ} \mathrm{C}$ for $6 \mathrm{~h}$, the specimen was cleaned with distilled water, dried with a cold air blaster, and then the SEM images were recorded using JEOL JSM-6380 LA analytical scanning electron microscope.

2.2.4. FT-IR Spectroscopy. For the FTIR studies the N80 steel coupons were immersed in $15 \% \mathrm{HCl}$ containing optimum concentration of inhibitors (AMPT, APT, and ACPT) for $24 \mathrm{~h}$. The test coupons were then removed from the solution, washed thoroughly with distilled water and dried. The film formed on the N80 surface in the presence of the inhibitor was collected by nonmetallic scrapper from the surface of the steel for spectral analysis with Fourier transform infrared spectroscopy (FT-IR). FT-IR spectra were recorded between $4000 \mathrm{~cm}^{-1}$ and $400 \mathrm{~cm}^{-1}$, and the scraped films were recorded using a Perkin Elmer Model 2000, by KBr pellet method.

\section{Results and Discussion}

3.1. Weight Loss Measurement. Corrosion inhibition efficiency (IE\%) offered by inhibitors (AMPT, APT, and ACPT) has been evaluated by weight loss technique after $6 \mathrm{~h}$ of immersion at $303 \mathrm{~K}$ which is given in Table 3. From this table it is apparent that inhibition efficiency (IE\%) was increased with the increase in the concentration of the inhibitor [23]. The maximum of $82.3 \%$ inhibition efficiency was obtained at the 200 ppm inhibitor (AMPT) concentration. No considerable effect on the inhibition efficiency (IE\%) was observed by a further increase in the inhibitor concentration in the acid solution. From this table, the order of the inhibition efficiency follows the order AMPT > APT > ACPT. Corrosion inhibition studies were also carried out at different temperatures. 
TABLE 4: Corrosion parameters, namely, corrosion rate (CR), surface coverage ( $\theta$ ), and inhibition efficiency IE (\%) of N80 steel in $15 \% \mathrm{HCl}$ in the presence and the absence of the inhibitor at different temperatures, obtained from weight loss measurements.

\begin{tabular}{|c|c|c|c|c|c|c|c|c|c|c|c|c|c|}
\hline \multirow{2}{*}{ Inhibitor } & \multirow{2}{*}{$\begin{array}{l}\text { Conc } \\
(\mathrm{ppm})\end{array}$} & \multicolumn{3}{|c|}{$303 \mathrm{~K}$} & \multicolumn{3}{|c|}{$313 \mathrm{~K}$} & \multicolumn{3}{|c|}{$323 \mathrm{~K}$} & \multicolumn{3}{|c|}{$333 \mathrm{~K}$} \\
\hline & & CR (mmpy) & $\theta$ & IE $\%$ & CR (mmpy) & $\theta$ & IE $\%$ & CR (mmpy) & $\theta$ & IE $\%$ & CR (mmpy) & $\theta$ & IE $\%$ \\
\hline Blank & - & 2.672 & - & - & 9.084 & - & - & 17.943 & - & - & 60.348 & - & - \\
\hline \multirow{5}{*}{ AMPT } & 20 & 0.983 & 0.632 & 63.2 & 2.906 & 0.680 & 68.0 & 4.719 & 0.737 & 73.7 & 14.00 & 0.768 & 76.8 \\
\hline & 50 & 0.863 & 0.677 & 67.7 & 2.416 & 0.734 & 73.4 & 3.893 & 0.783 & 78.3 & 10.00 & 0.833 & 83.3 \\
\hline & 100 & 0.673 & 0.748 & 74.8 & 1.607 & 0.823 & 82.3 & 2.440 & 0.864 & 86.4 & 6.155 & 0.898 & 89.8 \\
\hline & 150 & 0.529 & 0.802 & 80.2 & 1.317 & 0.855 & 85.5 & 1.920 & 0.893 & 89.3 & 5.129 & 0.915 & 91.5 \\
\hline & 200 & 0.446 & 0.823 & 82.3 & 1.090 & 0.880 & 88.0 & 1.596 & 0.911 & 91.1 & 4.586 & 0.924 & 92.4 \\
\hline \multirow{5}{*}{$\mathrm{APT}$} & 20 & 1.060 & 0.603 & 60.3 & 3.148 & 0.653 & 65.3 & 5.678 & 0.683 & 68.3 & 16.66 & 0.724 & 72.4 \\
\hline & 50 & 0.948 & 0.645 & 64.5 & 2.831 & 0.688 & 68.8 & 4.670 & 0.739 & 73.9 & 12.69 & 0.789 & 78.9 \\
\hline & 100 & 0.790 & 0.704 & 70.4 & 2.128 & 0.766 & 76.6 & 3.583 & 0.800 & 80.0 & 9.975 & 0.839 & 83.9 \\
\hline & 150 & 0.600 & 0.775 & 77.5 & 1.769 & 0.805 & 80.5 & 3.019 & 0.832 & 83.2 & 8.189 & 0.864 & 86.4 \\
\hline & 200 & 0.552 & 0.793 & 79.3 & 1.349 & 0.851 & 85.1 & 2.486 & 0.861 & 86.1 & 6.914 & 0.894 & 89.4 \\
\hline \multirow{5}{*}{$\mathrm{ACPT}$} & 20 & 1.140 & 0.573 & 57.3 & 3.455 & 0.619 & 61.9 & 6.263 & 0.651 & 65.1 & 19.60 & 0.675 & 67.5 \\
\hline & 50 & 1.053 & 0.606 & 60.6 & 3.332 & 0.633 & 63.3 & 5.363 & 0.701 & 70.1 & 14.83 & 0.754 & 75.4 \\
\hline & 100 & 0.869 & 0.674 & 67.4 & 2.503 & 0.725 & 72.5 & 4.419 & 0.754 & 75.4 & 12.40 & 0.794 & 79.4 \\
\hline & 150 & 0.708 & 0.735 & 73.5 & 2.082 & 0.770 & 77.0 & 3.676 & 0.795 & 79.5 & 10.72 & 0.822 & 82.2 \\
\hline & 200 & 0.649 & 0.757 & 75.7 & 1.637 & 0.819 & 81.9 & 3.136 & 0.825 & 82.5 & 8.762 & 0.855 & 85.5 \\
\hline
\end{tabular}

Corrosion parameters, namely, corrosion rate $(\mathrm{CR})$, surface coverage $(\theta)$, and inhibition efficiency (IE \%) of N80 steel in $15 \% \mathrm{HCl}$ in the presence and absence of inhibitor at different temperature, obtained from weight loss measurements, are shown in Table 4. As shown from this table, by increasing the concentration of the inhibitor, corrosion rate decreases; as a result, the inhibition efficiency was increased with rise in temperature [24]. For all concentrations of AMPT, the systems at $333 \mathrm{~K}$ gave the highest efficiencies. The maximum efficiency of $92 \%$ was obtained for $200 \mathrm{ppm}$ AMPT at $333 \mathrm{~K}$. The variation in corrosion rate with different concentration of thiadiazole derivatives in $15 \% \mathrm{HCl}$ at different temperature is shown in Figure 1. It is evident from Figure 1 that the inhibitor (AMPT, APT, and ACPT) has shown remarkable corrosion inhibition at a higher temperature. The variation of inhibition efficiency with the temperature is shown in Figure 2. From this figure, order of the inhibition efficiency of thiadiazole derivatives is as follows: AMPT $>$ APT $>$ ACPT. High efficiency of these compounds was attributed to the presence of extensively delocalized $\pi$ electrons of the phenyl rings, planarity, and the presence of lone pair of electrons on $\mathrm{N}$ and $\mathrm{S}$ atoms which favored a greater adsorption of inhibitors on the metal surface [25].

3.1.1. Thermodynamic and Activation Parameters. Thermodynamic and activation parameters play important role in understanding the inhibitive mechanism. The weight loss measurements were done in the temperature range of 303$333 \mathrm{~K}$ in the absence and the presence of different concentrations of inhibitors (AMPT, APT, and ACPT) in $15 \% \mathrm{HCl}$ for N80 steel. The apparent activation energy $\left(E_{a}\right)$ for dissolution
TABLE 5: Activation parameter for $\mathrm{N} 80$ in $15 \% \mathrm{HCl}$ solution in the absence and the presence of the inhibitor obtained from weight loss measurements.

\begin{tabular}{lcccc}
\hline Inhibitor & $\begin{array}{c}\text { Concentration } \\
(\mathrm{ppm})\end{array}$ & $\begin{array}{c}E_{a} \\
\left(\mathrm{~kJ} \mathrm{~mol}^{-1}\right)\end{array}$ & $\begin{array}{c}\Delta H^{*} \\
\left(\mathrm{~kJ} \mathrm{~mol}^{-1}\right)\end{array}$ & $\begin{array}{c}\Delta S^{*} \\
\left(\mathrm{Jmol}^{-1} \mathrm{~K}^{-1}\right)\end{array}$ \\
\hline Blank & - & 85.06 & 84.14 & 40.99 \\
\hline \multirow{3}{*}{ AMPT } & 20 & 72.93 & 66.09 & -26.78 \\
& 50 & 66.67 & 64.75 & -32.29 \\
& 100 & 60.32 & 62.80 & -40.62 \\
& 150 & 62.32 & 59.13 & -54.68 \\
& 200 & 63.78 & 49.40 & -88.48 \\
\hline \multirow{3}{*}{ APT } & 20 & 75.40 & 71.61 & -8.63 \\
& 50 & 70.50 & 66.87 & -24.38 \\
& 100 & 70.15 & 65.50 & -30.71 \\
& 150 & 72.25 & 67.63 & -25.73 \\
& 200 & 69.41 & 66.00 & -32.34 \\
\hline \multirow{3}{*}{ ACPT } & 20 & 78.53 & 71.73 & -6.60 \\
& 50 & 72.64 & 68.45 & -18.37 \\
& 100 & 72.66 & 68.72 & -19.13 \\
& 150 & 74.13 & 69.77 & -17.30 \\
& 200 & 71.15 & 69.44 & -20.50 \\
\hline
\end{tabular}

of $\mathrm{N} 80$ steel in $15 \% \mathrm{HCl}$ can be expressed using the Arrhenius equation,

$$
\log \mathrm{CR}=\frac{-E_{a}}{2.303 R T}+\log A,
$$




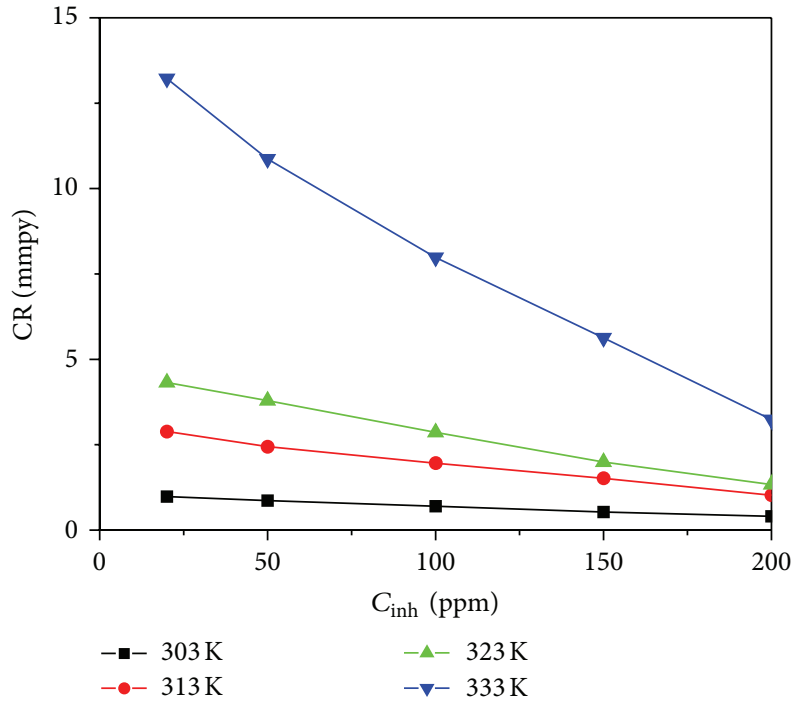

(a)

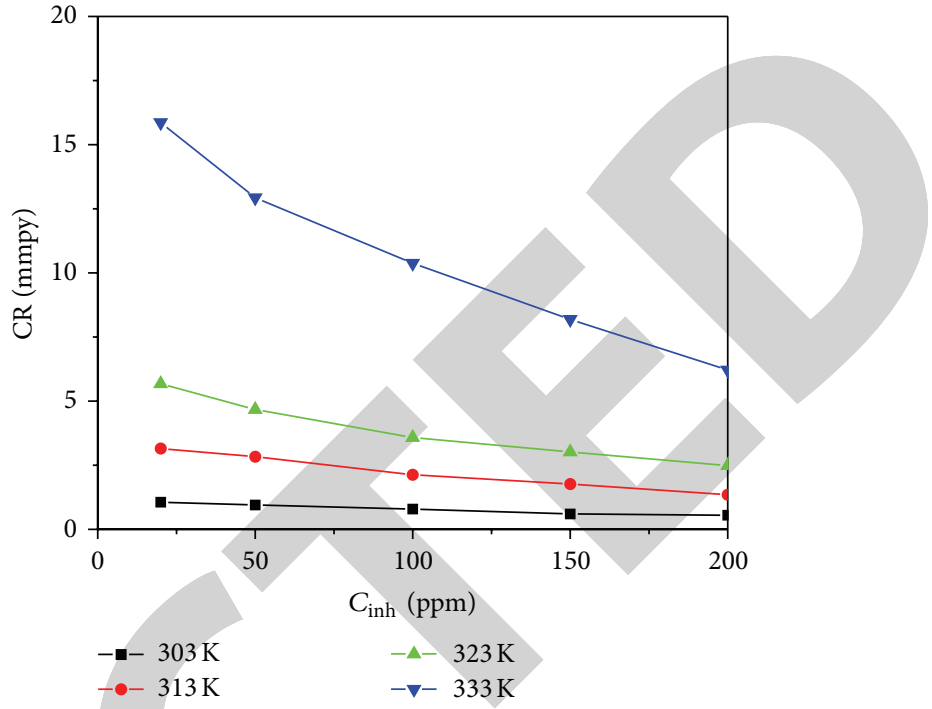

(b)

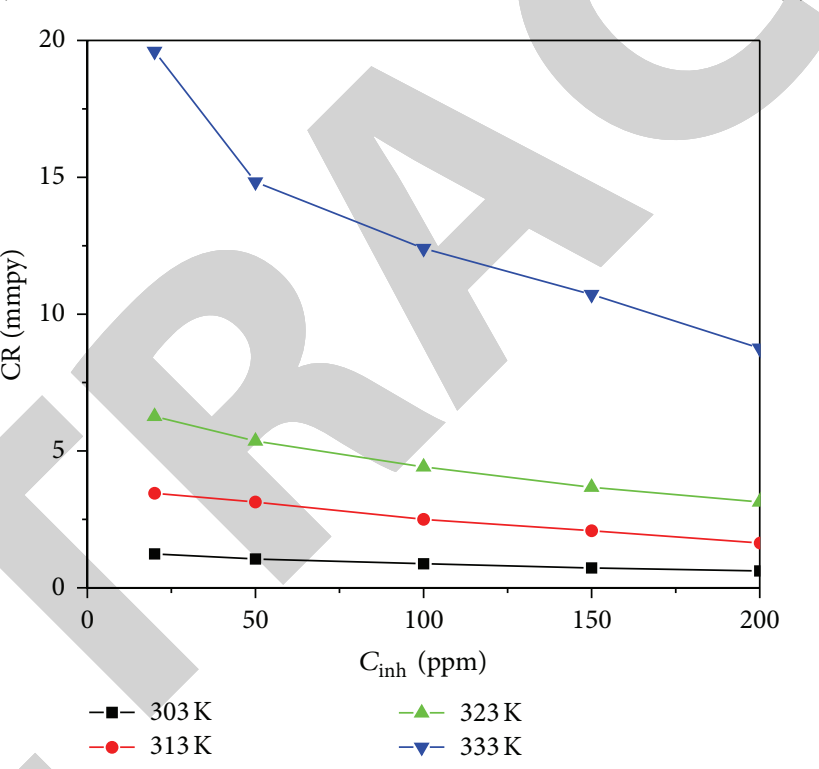

(c)

FIGURE 1: A plot of corrosion rate versus inhibitor's concentrations at different temperatures. (a) AMPT, (b) APT, and (c) ACPT.

where CR is the corrosion rate, $E_{a}$ is the apparent activation energy, $R$ is the molar gas constant $\left(8.314 \mathrm{~J} \mathrm{~K}^{-1} \mathrm{~mol}^{-1}\right), T$ is the absolute temperature, and $A$ is the Arrhenius preexponential factor. Figure 3 represents the Arrhenius plot of $\log \mathrm{CR}$ against $1 / T$ for the corrosion of $\mathrm{N} 80$ steel in $15 \% \mathrm{HCl}$ solution with or without the presence of AMPT, APT, and $\mathrm{ACPT}$ at concentrations ranging from $20 \mathrm{ppm}$ to $200 \mathrm{ppm}$. From Figure 3, the slope $\left(-E_{a} / R\right)$ of each individual line was determined, and the activation energy has been calculated by using $\left(E_{a}=(\right.$ slope $\left.) \times 2.303 \times R\right)$ and the values of $E_{a}$ were summarized in Table 5. It is evident from Table 5 that the decrease in activation energy $E_{a}$ indicates the retardation in corrosion rate which could have occurred because of the adsorption of the inhibitors at the surface of the metal [26].
The value of enthalpy of activation of the $\Delta H^{*}$ and the entropy of activation $\Delta S^{*}$ can be calculated by using the following formula:

$$
\mathrm{CR}=\frac{R T}{N h} \exp \left(\frac{\Delta S^{*}}{R}\right) \exp \left(-\frac{\Delta H^{*}}{R T}\right)
$$

where $\mathrm{CR}$ is the corrosion rate, $H^{*}$ is the enthalpy of activation, $S^{*}$ is the entropy of activation, $h$ is Planck's constant, and $N$ is the Avogadro number, respectively.

A plot of $\log (\mathrm{CR} / T)$ against $1 / T$ (Figure 4) gave straight lines with slope of $\left(-\Delta H^{*} / 2.303 R\right)$ and intercept of (log $\left.R / N h+\Delta S^{*} / 2.303 R\right)$ from which the activation thermodynamic parameters $\left(\Delta H^{*}\right.$ and $\left.\Delta S^{*}\right)$ are estimated and listed in Table 5. The results which are presented in Table 5 show that 
TABLE 6: Electrochemical parameter and percentage inhibition efficiency obtained from polarisation studies for $\mathrm{N} 80$ steel in $15 \% \mathrm{HCl}$ solution in the presence or the absence of the inhibitors at $303 \mathrm{~K}$.

\begin{tabular}{|c|c|c|c|c|c|c|}
\hline Inhibitor & Concentration (ppm) & $E_{\text {corr }}\left(\mathrm{mV}_{\mathrm{SCE}}\right)$ & $b_{a}\left(\mathrm{mV} \mathrm{dec}{ }^{-1}\right)$ & $b_{c}\left(\mathrm{mV} \mathrm{dec}{ }^{-1}\right)$ & $I_{\text {corr }}\left(\mu \mathrm{A} \mathrm{cm}^{-2}\right)$ & $\%$ IE \\
\hline Blank & - & -427 & 95 & 135 & 573 & \\
\hline \multirow{5}{*}{$\mathrm{AMPT}$} & 20 & -434 & 55 & 104 & 178 & 68.87 \\
\hline & 50 & -437 & 64 & 82 & 160 & 72.02 \\
\hline & 100 & -438 & 77 & 93 & 134 & 76.54 \\
\hline & 150 & -445 & 157 & 142 & 95 & 83.37 \\
\hline & 200 & -447 & 111 & 128 & 80 & 86.51 \\
\hline \multirow{5}{*}{ APT } & 20 & -428 & 74 & 147 & 203 & 64.52 \\
\hline & 50 & -432 & 61 & 73 & 182 & 68.21 \\
\hline & 100 & -433 & 53 & 84 & 154 & 73.21 \\
\hline & 150 & -436 & 92 & 98 & 106 & 81.58 \\
\hline & 200 & -438 & 108 & 44 & 103 & 82.03 \\
\hline \multirow{5}{*}{$\mathrm{ACPT}$} & 20 & -430 & 68 & 102 & 229 & 60.02 \\
\hline & 50 & -431 & 75 & 91 & 205 & 64.05 \\
\hline & 100 & -432 & 88 & 79 & 177 & 69.07 \\
\hline & 150 & -434 & 97 & 108 & 133 & 76.81 \\
\hline & 200 & -436 & 118 & 156 & 114 & 80.07 \\
\hline
\end{tabular}

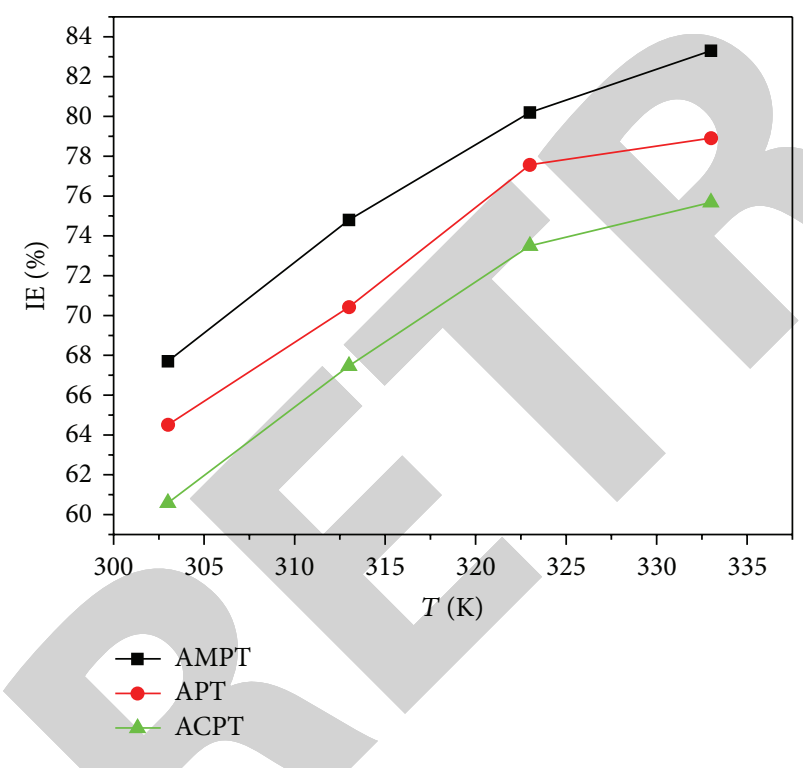

FIGURE 2: Variation of inhibition efficiency of the studied compounds with the temperature containing optimum concentration of inhibitor.

the enthalpy of activation is all positive. The positive sign of the enthalpy reflects the endothermic nature of the N80 steel dissolution process [27]. The negative value of $\Delta S^{*}$ (Table 5) for all the three inhibitors indicates that activated complex in the rate determining step represents an association rather than a dissociation step, meaning that a decrease in disorder takes place during the course of transition from the reactant to the activated complex, and the positive value of $\Delta S^{*}$ refers to an increase in the disorder [28].
3.2. Potentiodynamic Polarization Measurements. The anodic and cathodic polarisation curves for the corrosion of N80 steel in $15 \% \mathrm{HCl}$ in the presence and the absence of varying concentrations of inhibitors (AMPT, APT, and ACPT) at $303 \mathrm{~K}$ are shown in Figure 6. The linear Tafel segments of the cathodic and anodic curves were extrapolated to the point of intersection to obtain the corrosion potential $\left(E_{\text {corr }}\right)$ and corrosion current density $\left(i_{\text {corr }}\right)$. The electrochemical parameters such as corrosion potential $\left(E_{\text {corr }}\right)$, corrosion current density $\left(i_{\text {corr }}\right)$, anodic $\left(b_{a}\right)$ and cathodic $\left(b_{c}\right)$ Tafel slope, and percentage inhibition efficiency (IE\%) determined from polarisation curve are summarized in Table 6 . The data in Table 6 clearly show that the current density decreases with the presence of thiadiazole inhibitors (AMPT, APT, and $\mathrm{ACPT}$ ); this indicated that inhibitors adsorbed on the metal surface, and hence the inhibition efficiency increases with the increase in the inhibitor concentration up to an optimum value. Thereafter, the increase in the inhibitor concentration resulted in negligible increase in inhibition efficiency and the presence of inhibitor caused small changes in $\left(E_{\text {corr }}\right)$ value. This implies that the inhibitor acts as a mixed-type inhibitor, affecting both anodic and cathodic reactions [29]. According to Li et al. [30], if the displacement in $E_{\text {corr }}$ is more than $\pm 85 \mathrm{mV} / \mathrm{SCE}$ relating to $E$ (corrosion potential of the blank), the inhibitor can be considered as a cathodic or anodic type. If the change in $E_{\text {corr }}$ is less than $85 \mathrm{mV}$, the corrosion inhibitor may be regarded as a mixed type. But the maximum displacement in the present case is less than $20 \mathrm{mV} / \mathrm{SCE}$, which indicates that AMPT, $\mathrm{APT}$, and ACPT act as mixed-type inhibitors. It is concluded that the inhibitor's molecules retard the corrosion process without changing the mechanism of corrosion process in the medium of investigation. However, the shift of $E_{\text {corr }}$ values towards positive direction on increasing the concentration 

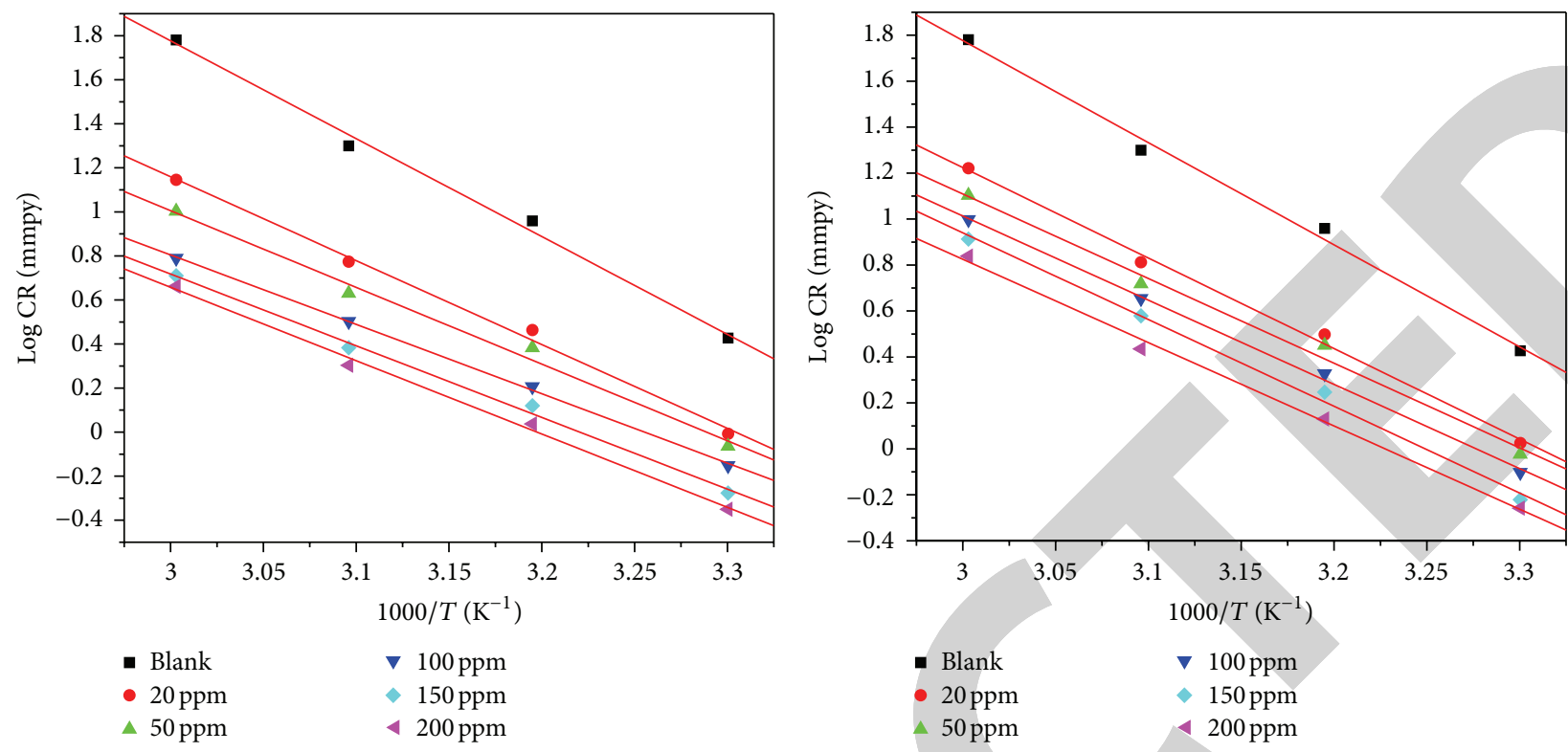

(a)

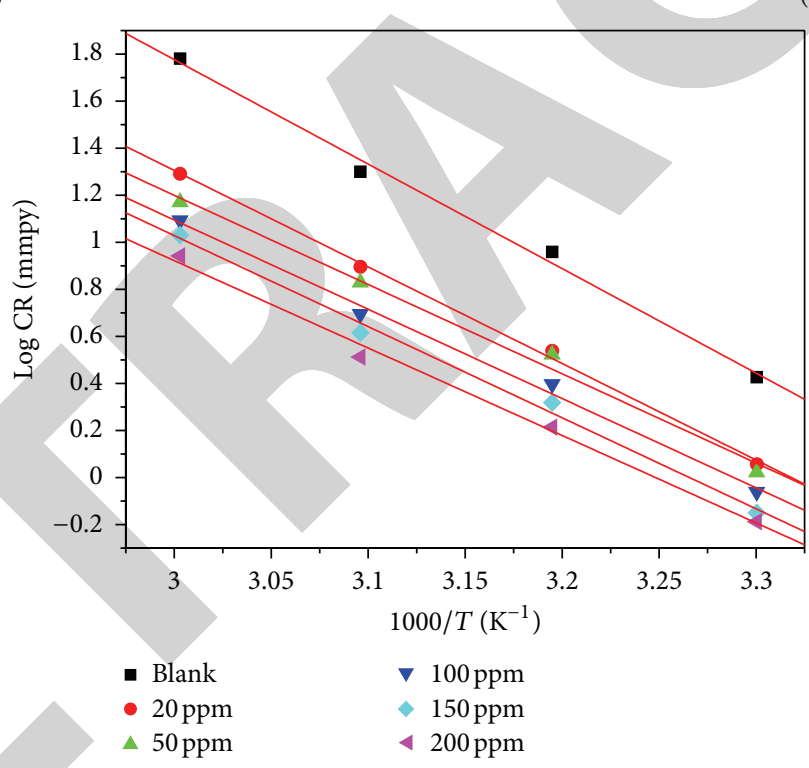

(c)

Figure 3: Arrhenius plots of log CR versus 1000/T for N80 steel corrosion in 15\% HCl (a) AMPT, (b) APT, and (c) ACPT.

of thiadiazole derivatives suggests anodic control over the reaction.

3.3. Electrochemical Impedance Spectroscopy (EIS). Nyquist plots of $\mathrm{N} 80$ steel in $15 \% \mathrm{HCl}$ solution in the absence and the presence of different concentrations of AMPT, APT, and ACPT at $303 \mathrm{~K}$ are shown in Figures $7(\mathrm{a}), 7(\mathrm{~b})$, and $7(\mathrm{c})$. It follows from Figures 7(a), 7(b), and 7(c) that a high frequency (HF) depressed charge-transfer semicircle was observed. The experimental data obtained from these plots are fitted by the equivalent electrical circuit shown in Figure 8. Such an equivalent circuit was also discussed by several researchers, who obtained similar depressed semicircles with single time constant due to surface heterogeneity of corrosion product covering the surface at random sites [31-33]. The chargetransfer resistance $\left(R_{\mathrm{ct}}\right)$ values were calculated from the difference in impedance at low and high frequencies. The values of electrochemical double-layer capacitance $\left(C_{\mathrm{dl}}\right)$ were calculated at the frequency $f_{\max }$, at which the imaginary component of the impedance is maximal $\left(-Z_{i}\right)$ by the following equation:

$$
C_{\mathrm{dl}}=\frac{1}{2 \pi f_{\max } R_{\mathrm{ct}}}
$$

The constant phase element of double-layer (CPE) is mathematically expressed as

$$
Z_{\mathrm{CPE}}=Y_{0}^{-1}(i)^{-n},
$$



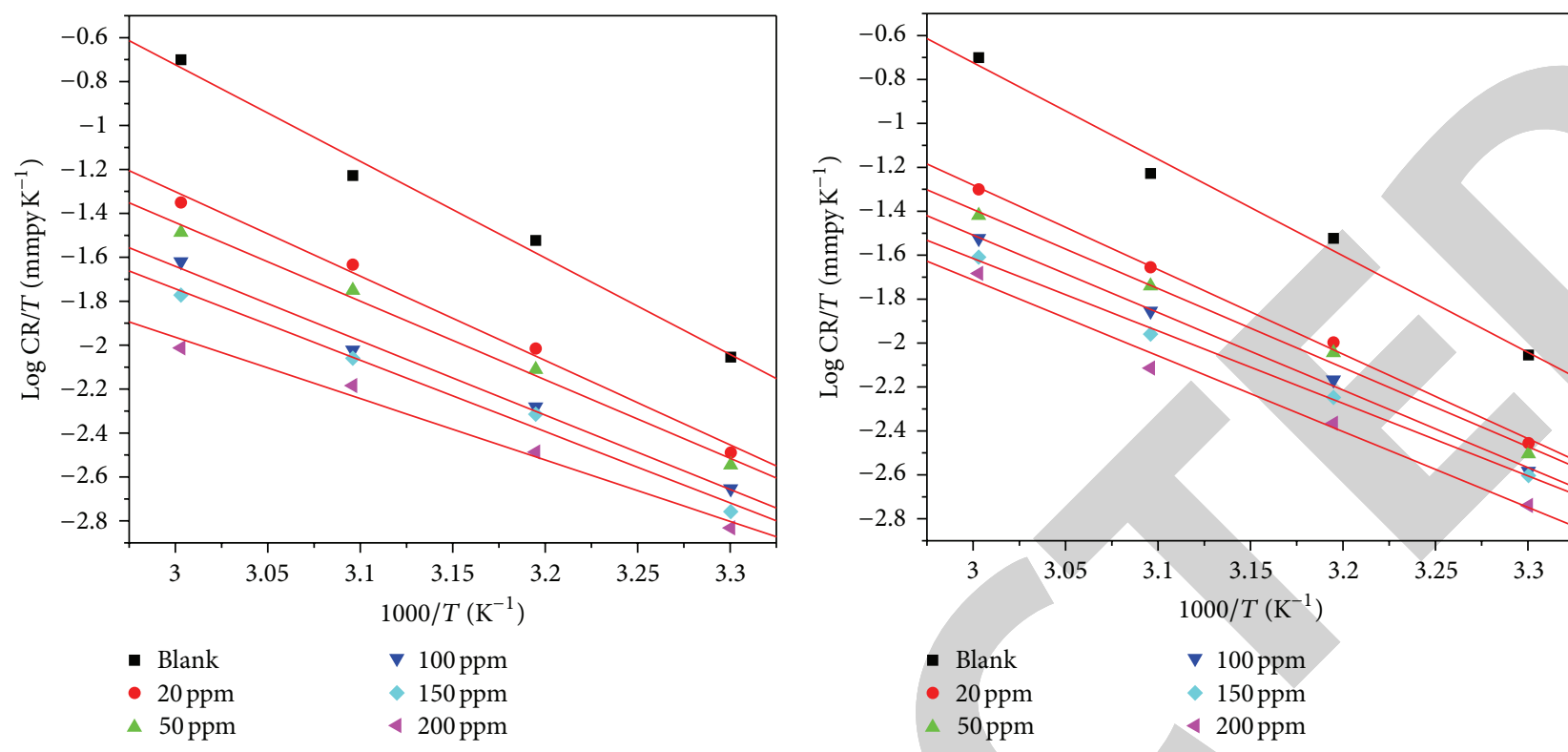

(a)

(b)

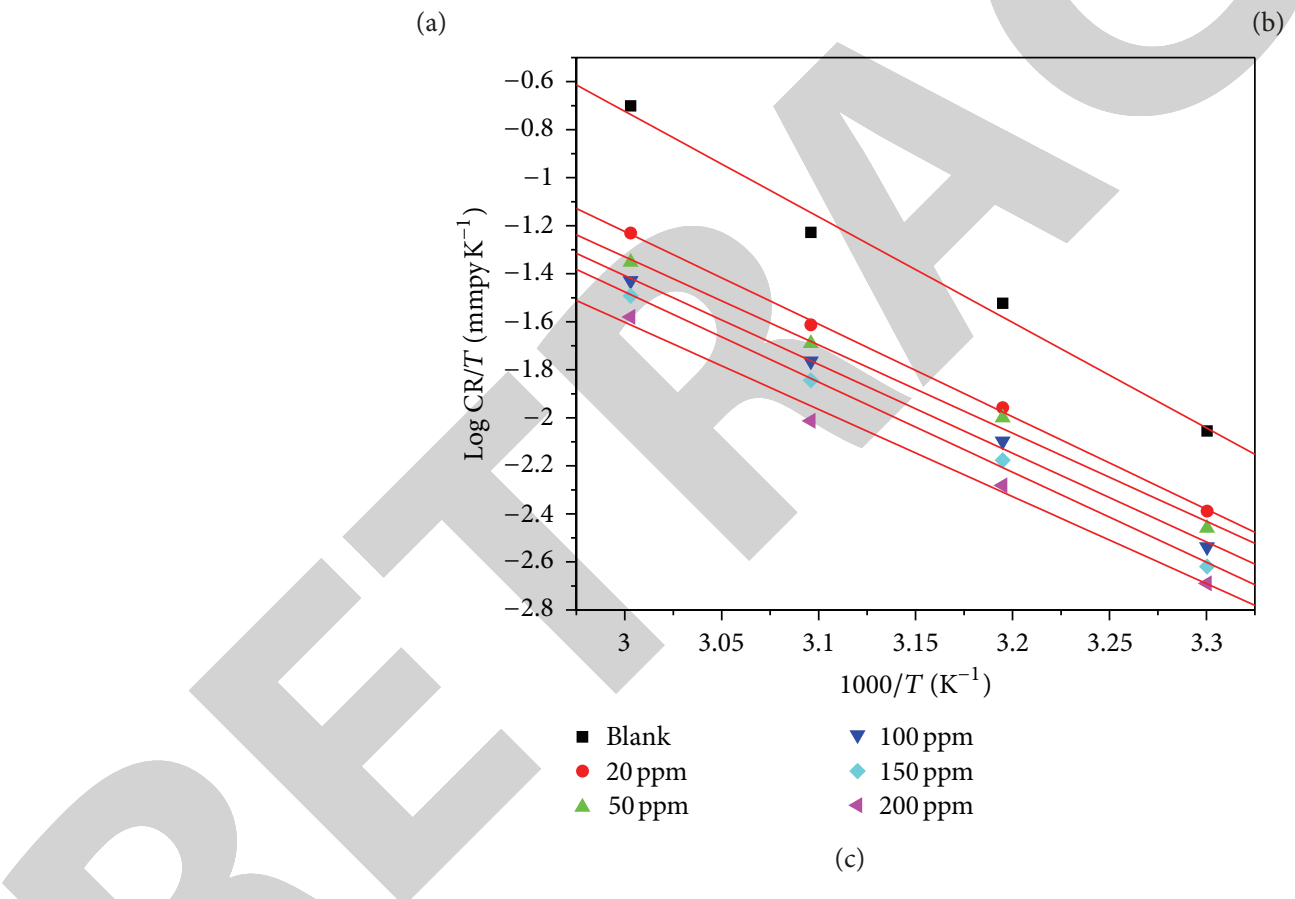

FIGURE 4: Transition state plot of $\log \mathrm{CR} / \mathrm{T}$ versus $1000 / \mathrm{T}$ for $\mathrm{N} 80$ steel in $15 \% \mathrm{HCl}$ at different concentrations of (a) AMPT, (b) APT, and (c) ACPT.

where $Y_{0}$ is a proportionality factor and " $n$ " has the meaning of phase shift. The value of " $n$ " represents the deviation from the ideal behavior and it lies between 0 and 1 .

The charge transfer resistance $\left(R_{\mathrm{ct}}\right)$, double-layer capacitance $\left(C_{\mathrm{dl}}\right)$ obtained from the Nyquist plots, and the calculated inhibition efficiency values (IE\%) are shown in Table 7. It is clear that the value of $R_{\mathrm{ct}}$ increases with increasing the concentration of the inhibitor, indicating that the corrosion rate decreases in the presence of the inhibitor [34]. It is also clear that the value of $C_{\mathrm{dl}}$ decreases on the addition of inhibitors, indicating a decrease in the local dielectric constant and/or an increase in the thickness of the electrical double layer, suggesting that the inhibitor molecules function by the formation of the protective layer at the metal surface [35]. So, the changes in $R_{\mathrm{ct}}$ and $C_{\mathrm{dl}}$ values were caused by the steady replacement of the water molecules by the adsorption of inhibitor on mild steel surface, reducing the extent of dissolution [36]. The maximum inhibition efficiency was obtained for AMPT at $200 \mathrm{ppm}$ concentration. Both electrochemical methods (polarization measurement and EIS study) offered nearly the same trend.

3.4. Adsorption Isotherm. Basic information on the interaction between the organic inhibitors and the N80 steel 


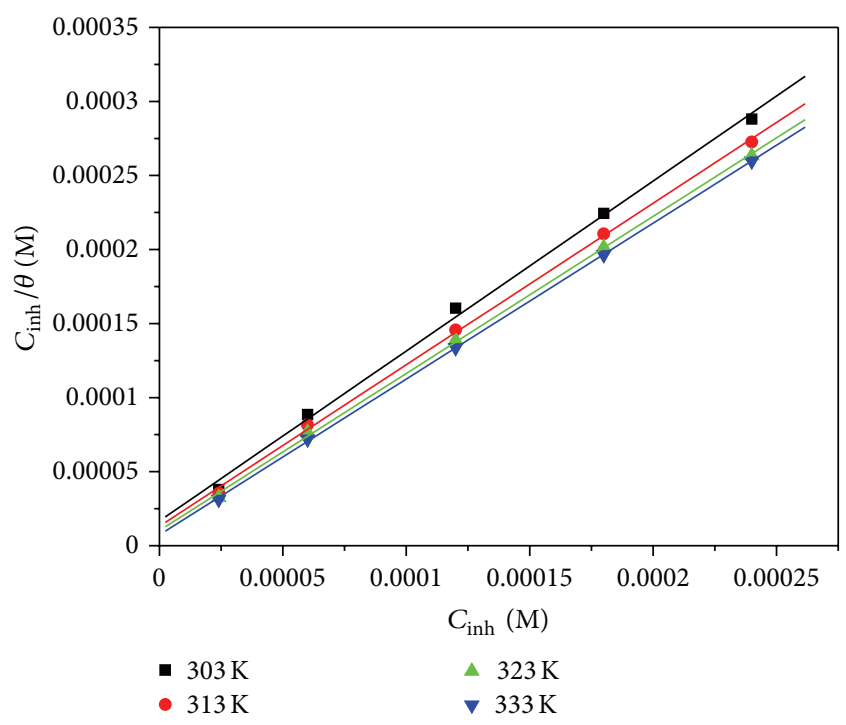

(a)

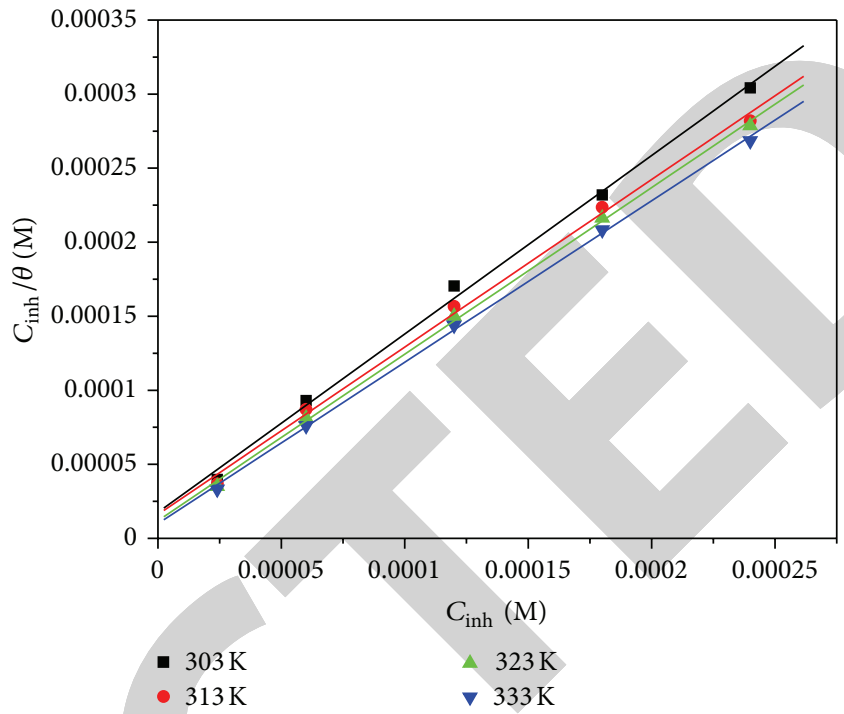

(b)

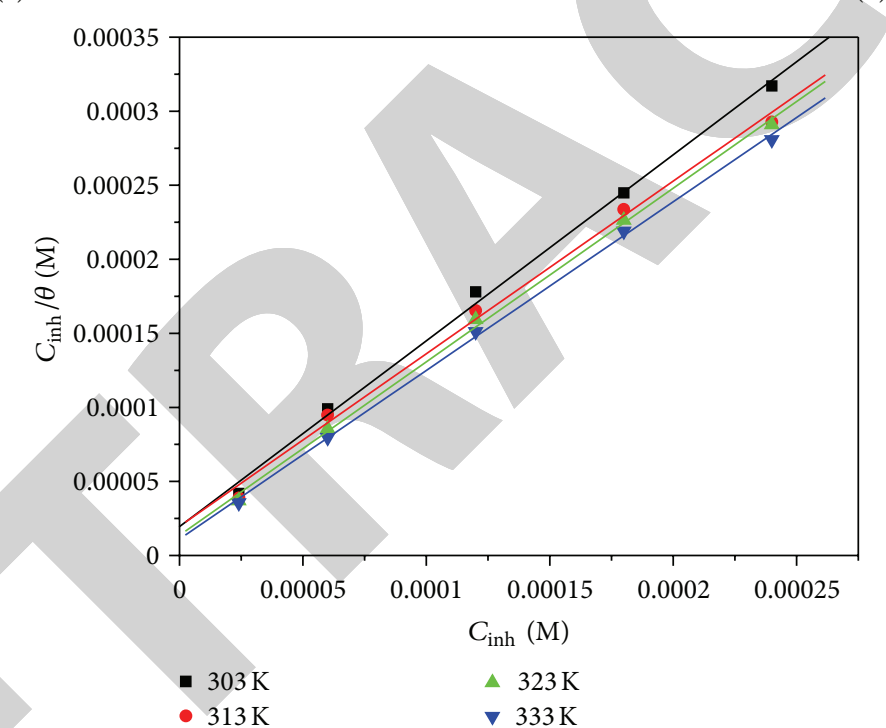

(c)

Figure 5: Langmuir plots of $\left(C_{\text {inh }} / \theta\right)$ versus $C_{\text {inh }}$ for (a) AMPT, (b) APT, and (c) ACPT.

surface is obtained from various isotherms. Adsorption of these organic inhibitors has displaced the water molecule from the metal surface. The most commonly used adsorption isotherms are Langmuir, Temkin, and Frumkin. By far, the best fit was obtained with the Langmuir adsorption isotherm. The degree of surface coverage $(\theta)$ for different concentrations of inhibitor in $15 \%$ hydrochloric acid has been evaluated by the weight loss value. According to the Langmuir adsorption isotherm, the surface coverage $(\theta)$ is related to the inhibition concentration by the following equation:

$$
\frac{C_{\mathrm{inh}}}{\theta}=\frac{1}{K_{\mathrm{ads}}}+C_{\mathrm{inh}},
$$

where $C_{\text {inh }}$ is the inhibitor concentration and $K_{\mathrm{ads}}$ is the equilibrium constant for adsorption-desorption process.
A plot of $\left(C_{\text {inh }} / \theta\right)$ versus $C_{\text {inh }}$ (Figure 5) gives a straight line with an average correlation coefficient $\left(R^{2}\right),\left(R^{2}=0.998\right.$, 0.997, and 0.999) for AMPT, APT, and ACPT, respectively, at $303 \mathrm{~K}$ which suggests that the adsorption obeys Langmuir adsorption isotherm. From the intercept, $K_{\mathrm{ads}}$ is calculated, and by using the value of $K_{\text {ads }}$ the value of $\Delta G_{\text {ads }}^{0}$ was calculate by the following equation:

$$
\Delta G_{\mathrm{ads}}^{0}=-R T \ln \left(55.5 K_{\mathrm{ads}}\right),
$$

where $R$ is the gas constant and $T$ is the absolute temperature (K). The value of 55.5 is the molar concentration of water in solution in $\mathrm{mol} \mathrm{L}^{-1}$. In the present study a large value of $K_{\mathrm{ads}}$ was found for all the three studied inhibitors indicating the strong adsorption of inhibitor molecules at the surface of N80 steel. The values of $\Delta G_{\text {ads }}^{0}$ were $-37.5,-35.2$, and 


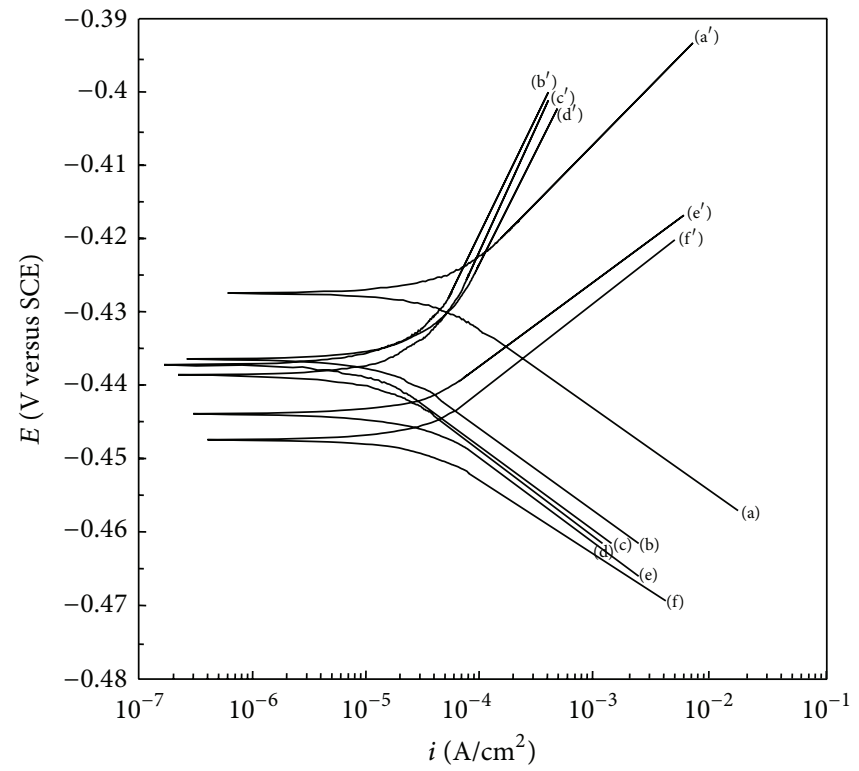

( $\left.\mathrm{aa}^{\prime}\right)$ Blank $\left(\mathrm{bb}^{\prime}\right) 20 \mathrm{ppm}$ AMPT (cc') $50 \mathrm{ppm}$ AMPT $\left(\mathrm{dd}^{\prime}\right) 100$ ppm AMPT $\left(\mathrm{e}^{\prime}\right) 150 \mathrm{ppm}$ AMPT $\left(\mathrm{ff}^{\prime}\right) 200 \mathrm{ppm}$ AMPT

(a)

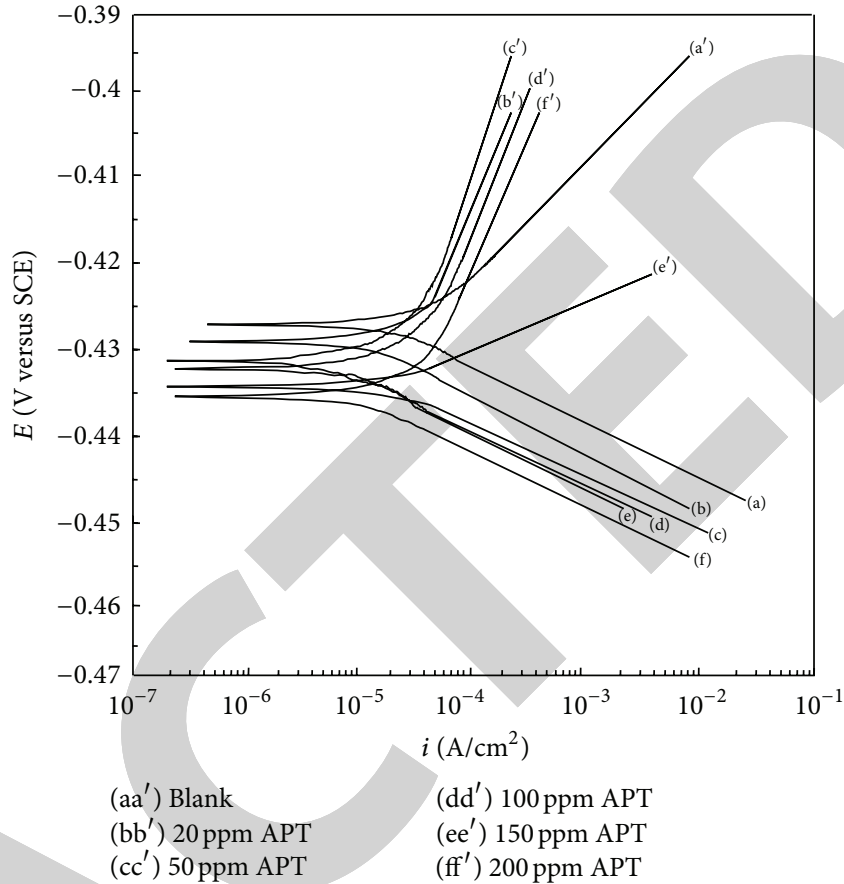

(b)

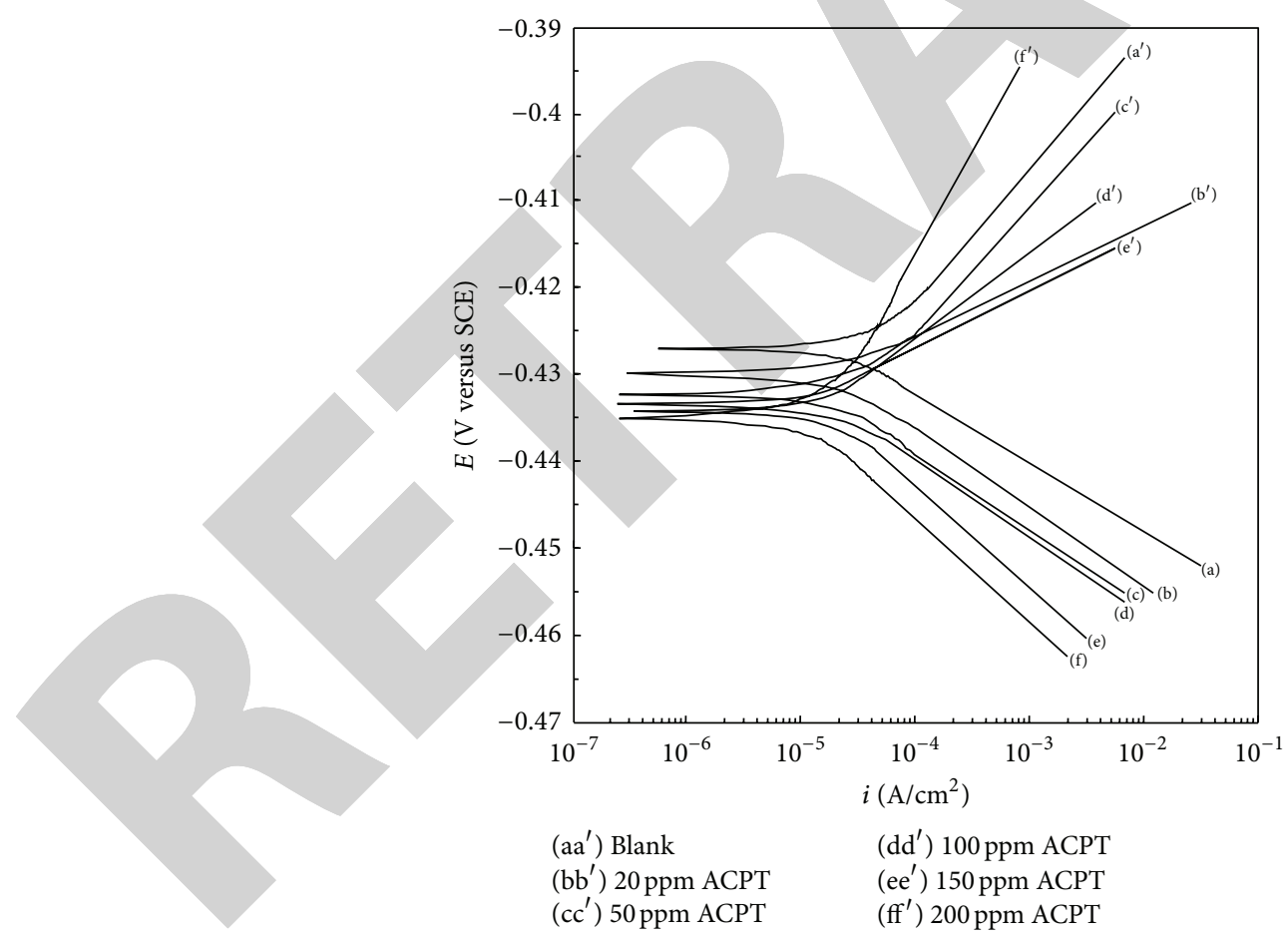

(c)

Figure 6: Potentiodynamic polarization curves for $\mathrm{N} 80$ steel in $15 \% \mathrm{HCl}$ in the presence and the absence of inhibitors at $303 \mathrm{~K}$. (a) AMPT, (b) APT, and (c) ACPT.

$-32.1 \mathrm{~kJ} / \mathrm{mol}$ for AMPT, APT, and ACPT, respectively. The negative values of $\Delta G_{\text {ads }}^{0}$ indicate a spontaneous adsorption process and stability of the adsorbed film of (AMPT, APT, and ACPT) on N80 surface [37]. It is generally accepted that for the values of $\Delta G_{\text {ads }}^{0}$ up to $-20 \mathrm{~kJ} / \mathrm{mol}$, the types of adsorption were regarded as physisorption; the inhibition acts due to the electrostatic interactions between the charged molecules and the charged metallic surfaces, while the values around $-40 \mathrm{~kJ} / \mathrm{mol}$ or smaller were seen as chemisorption, which is due to the charge sharing or a transfer from the 


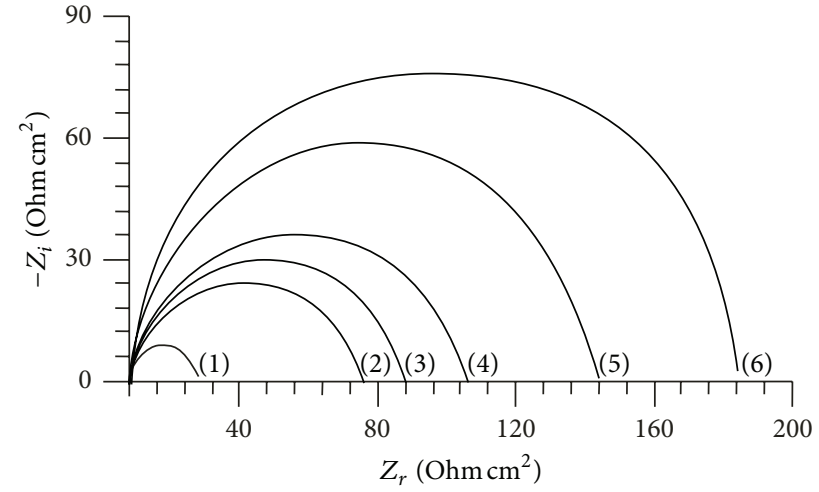
(1) Blank
(2) $20 \mathrm{ppm}$ AMPT
(3) $50 \mathrm{ppm}$ AMPT
(6) $200 \mathrm{ppm}$ AMPT

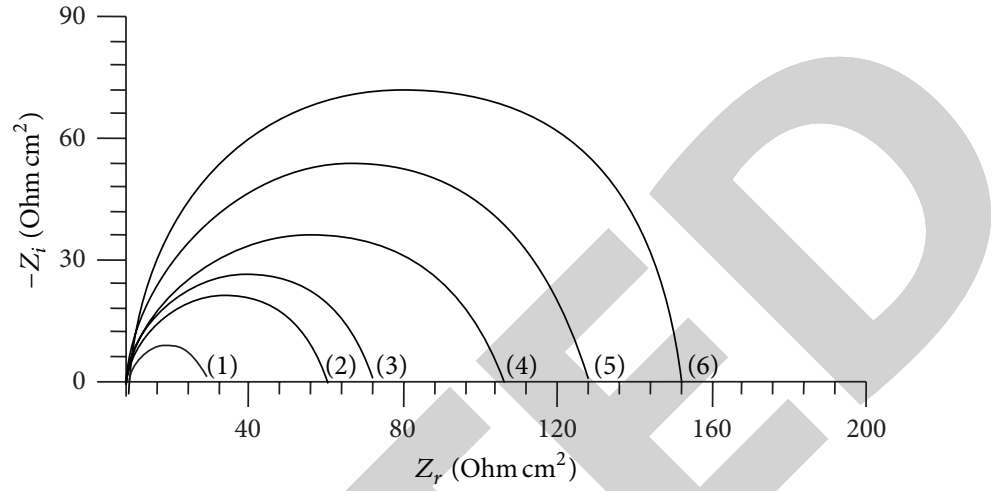

(1) Blank

(2) $20 \mathrm{ppm}$ APT

(4) $100 \mathrm{ppm}$ APT

(3) $50 \mathrm{ppm} \mathrm{APT}$

(5) 150 ppm APT

(6) $200 \mathrm{ppm}$ APT

(a)

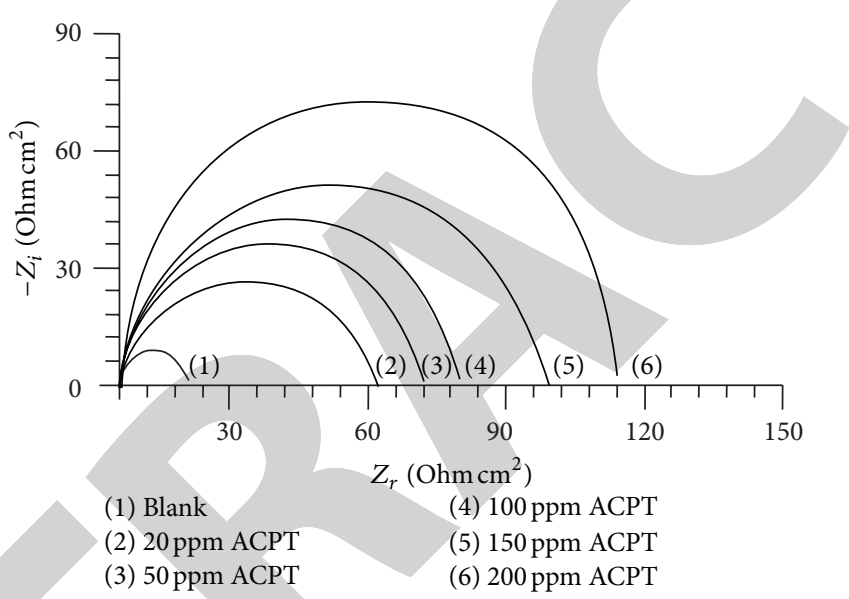

(b)

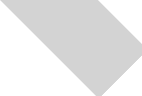

(c)

FIgURE 7: Nyquist plot for N80 steel in 15\% $\mathrm{HCl}$ acid containing various concentrations of (a) AMPT, (b) APT, and (c) ACPT. (1) 0 ppm (2) $50 \mathrm{ppm}$ (3) $100 \mathrm{ppm}$ (4) $150 \mathrm{ppm}$, and (5) $200 \mathrm{ppm}$ at $303 \mathrm{~K}$.

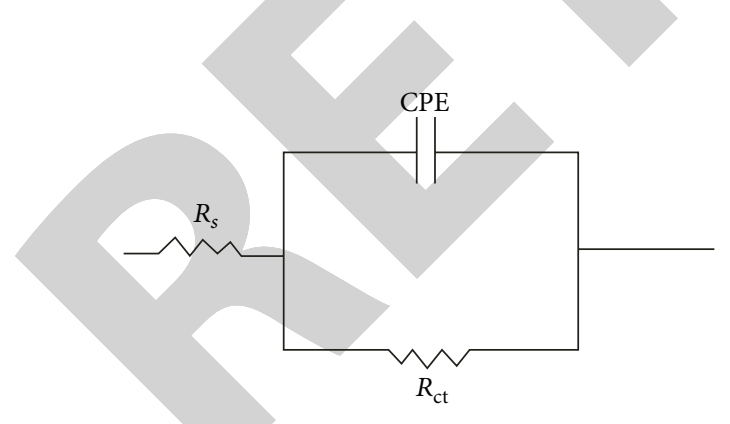

FIGURE 8: The electrochemical equivalent circuit used to fit the impedance measurements.

inhibitor's molecules to the metal surface to form a covalent bond [38, 39]. The values of $\Delta G_{\text {ads }}^{0}$ in our measurements range from -30 to $-40 \mathrm{~kJ} \cdot \mathrm{mol}^{-1}$; it is suggested that the adsorption of these molecules involves chemisorption.

The inhibition efficiency afforded by all the three inhibitors may be attributed to the presence of electron rich $(\mathrm{N}, \mathrm{S})$ atoms and delocalized $\pi$ electrons. The possible coordinating centres are unshared electron pair of nitrogen of $-\mathrm{NH}_{2}$ group, nitrogen of thiadiazole ring, $\mathrm{C}=\mathrm{N}$ group, and $\pi$-electrons of phenyl and thiadiazole rings. The participation of phenyl ring during the adsorption of the inhibitors may be shown by higher $\%$ IE value in case of methoxy substituents having $+\mathrm{I}$ effect and lower values for chlorosubstituent with - I effect.

3.5. Scanning Electron Microscopy (SEM). The surface morphology of mild steel specimens exposed to $15 \% \mathrm{HCl}$ solutions in the absence and presence of $200 \mathrm{ppm}$ of AMPT are shown in Figures 9(a), 9(b), and 9(c). Figure 9(a) shows SEM image of polished bare N80 steel surface. Figure 9(b) reveals that the surface is severely corroded, and there is formation of different forms of corrosion products (iron oxides) on the surface in the absence of the inhibitor, and the entire surface is covered by a scale-like black corrosion product. The morphological feature of the inhibited surface with the addition of $200 \mathrm{ppm}$ of AMPT is shown in Figure 9(c). On comparing these micrographs, it appears, that in the presence of inhibitors, the surface of the test material has improved remarkably with respect to its smoothness. The smoothening 

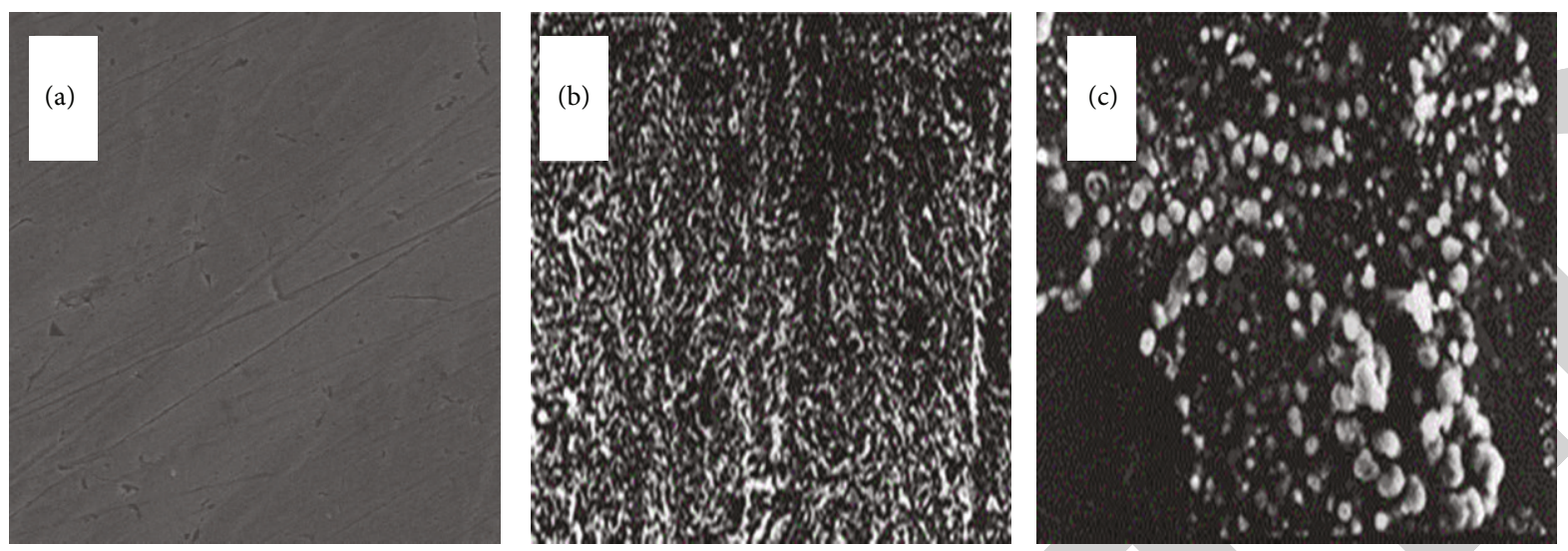

FIGURE 9: SEM image of $\mathrm{N} 80$ steel in $4 \mathrm{~N} \mathrm{HCl}$ solution after $6 \mathrm{~h}$ immersion at $303 \mathrm{~K}$ (a) before immersion (polished) and (b) after immersion without inhibitor and (c) with inhibitor (AMPT).

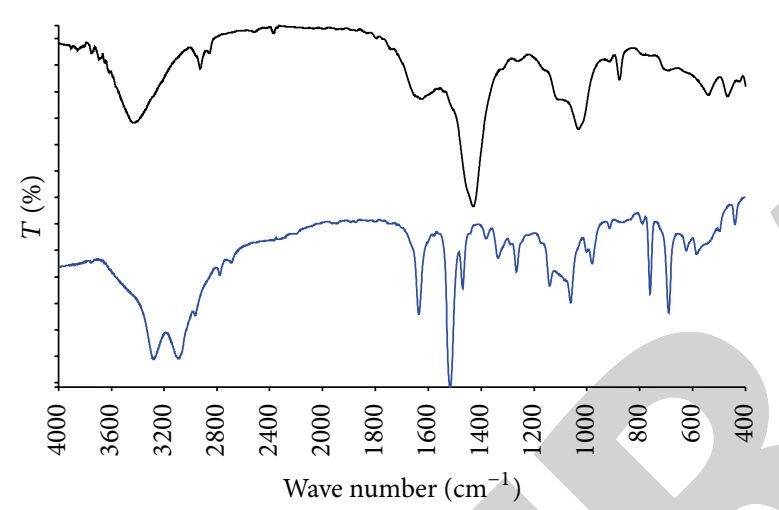

(a)

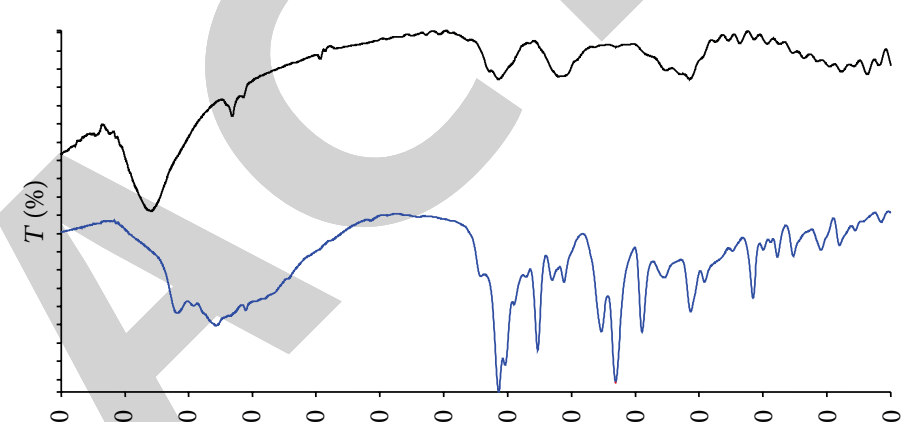

Wave number $\left(\mathrm{cm}^{-1}\right)$

(b)

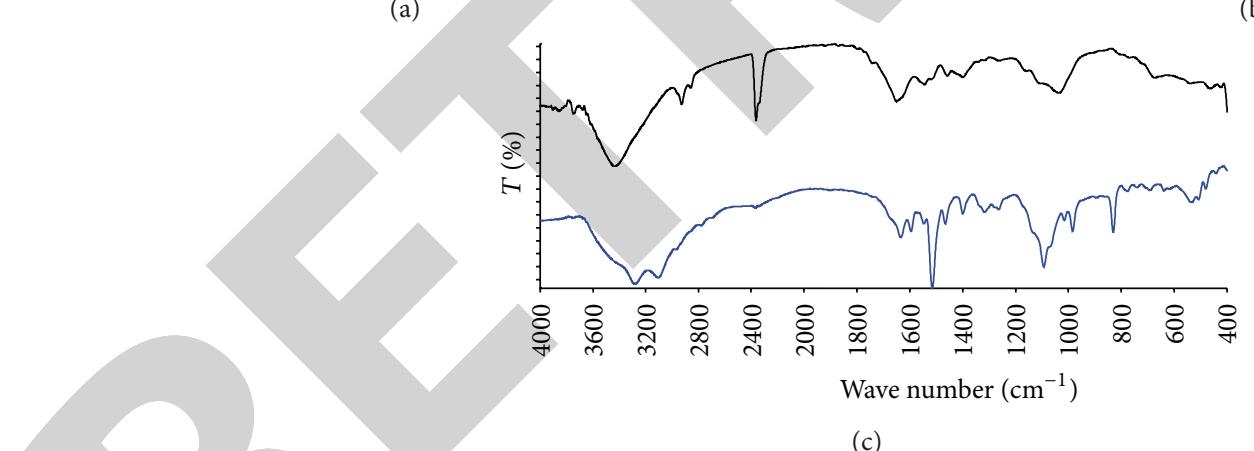

FIGURE 10: FTIR spectrum of the inhibitor (below), FT-IR spectrum of inhibitor adsorbed on metal surface (above). (a) AMPT, (b) APT, and (c) ACPT.

of the surface would have been caused by the adsorption of inhibitor molecules on it. But the closer look at such sites reveals that the inhomogeneities are due to the structural defects of the metal substrate and that these sites are also covered by the inhibitor film. This observation also accounts for the high inhibition efficiency values obtained during the weight loss studies of the inhibitor system.

3.6. FTIR Spectroscopic Analysis of Corrosion Product. The FTIR spectra of pure inhibitors and the surface films formed on N80 steel coupons immersed in $15 \% \mathrm{HCl}$ containing optimum concentration of inhibitors (AMPT, APT, and ACPT) for $6 \mathrm{~h}$ are presented in Figures 10(a), 10(b), and 10(c). The FTIR spectra of pure AMPT show band at $3290 \mathrm{~cm}^{-1}, 3135 \mathrm{~cm}^{-1}$, APT at $3355,3160 \mathrm{~cm}^{-1}$ and ACPT at $3280,3120 \mathrm{~cm}^{-1}$, which indicate the asymmetrical and symmetrical $\mathrm{N}-\mathrm{H}$ stretching vibrations for the amino group. Bands at $3280 \mathrm{~cm}^{-1}, 3125 \mathrm{~cm}^{-1}$ for AMPT, $3345,3148 \mathrm{~cm}^{-1}$ for APT, and $3272,3113 \mathrm{~cm}^{-1}$ for ACPT, respectively indicate the asymmetrical and symmetrical $\mathrm{N}-\mathrm{H}$ stretching vibration for amino group. Strong peaks observed at 1640, 1630, and $1635 \mathrm{~cm}^{-1}$ are attributed to the $\mathrm{N}-\mathrm{H}$ in plane bending 
TABLE 7: Electrochemical impedance parameters and percentage inhibition efficiency for $\mathrm{N} 80$ steel in $15 \% \mathrm{HCl}$ in the absence and the presence of the inhibitors at different concentrations at $303 \mathrm{~K}$.

\begin{tabular}{lcccc}
\hline Inhibitor & $\begin{array}{c}\text { Concentration } \\
(\mathrm{ppm})\end{array}$ & $\begin{array}{c}R_{\mathrm{ct}} \\
\left(\Omega \mathrm{cm}^{2}\right)\end{array}$ & $\begin{array}{c}C_{\mathrm{dl}} \\
\left(\mu \mathrm{F} \mathrm{cm}{ }^{2}\right)\end{array}$ & $\% \mathrm{IE}$ \\
\hline Blank & - & 25 & 252 & \\
\hline \multirow{3}{*}{ AMPT } & 20 & 74 & 158 & 66.32 \\
& 50 & 85 & 122 & 70.58 \\
& 100 & 110 & 87 & 77.25 \\
& 150 & 142 & 73 & 82.37 \\
& 200 & 178 & 67 & 85.97 \\
\hline \multirow{3}{*}{ APT } & 20 & 66 & 82 & 62.42 \\
& 50 & 75 & 66 & 67.71 \\
& 100 & 102 & 53 & 75.47 \\
& 150 & 126 & 32 & 80.13 \\
& 200 & 150 & 26 & 83.31 \\
\hline \multirow{3}{*}{ ACPT } & 20 & 63 & 71 & 60.52 \\
& 50 & 74 & 58 & 66.12 \\
& 100 & 80 & 41 & 68.58 \\
& 150 & 107 & 24 & 76.53 \\
& 200 & 134 & 20 & 81.03 \\
\hline
\end{tabular}

vibrations of the amino group in pure AMPT, APT, and ACPT, respectively. Strong peaks observed at 1626,1622 , and $1620 \mathrm{~cm}^{-1}$ are attributed to the $\mathrm{N}-\mathrm{H}$ in plane bending vibrations of the amino group in AMPT, APT, and ACPT, respectively. Strong bands at 1530,1520 , and $1525 \mathrm{~cm}^{-1}$ are attributed to the stretching vibration of the $\mathrm{C}=\mathrm{N}$ group in the ring in pure AMPT, APT, and ACPT, respectively. Strong bands at 1523,1512 , and $1514 \mathrm{~cm}^{-1}$ are attributed to the stretching vibration of the $\mathrm{C}=\mathrm{N}$ group in the ring in surface product of AMPT, APT, ACPT respectively. Peaks observed at 695,690 , and $680 \mathrm{~cm}^{-1}$ are attributed to the ring $\mathrm{C}-\mathrm{S}$ vibration for pur AMPT, APT, and ACPT, respectively. Peaks observed at 690,684 , and $670 \mathrm{~cm}^{-1}$ are attributed to the ring $\mathrm{C}-\mathrm{S}$ vibration for surface product of AMPT, APT, ACPT respectively. The presence of all the functional groups present in pure AMPT, APT, and ACPT in the spectrum of the surface product with a negative shift indicates the adsorption of inhibitors AMPT, APT, and ACPT at the surface of N80 steel.

\section{Conclusions}

(1) The synthesized thiadiazoles show good inhibition efficiencies for the corrosion of N80 steel in $15 \mathrm{wt} \%$ $\mathrm{HCl}$ solutions and the inhibition efficiency increases with increasing the concentration of these inhibitors and with the temperature. The increasing order of inhibiting performance of the inhibitors is in the order of: AMPT $>$ APT $>$ ACPT.

(2) Thiadiazoles inhibitors were found to be mixed-type inhibitors from Tafel polarization measurements.
While one equivalent structure model was selected to fit the experimental data of the impedance diagram (EIS). And the results are good in agreement with weight loss measurements.

(3) It is suggested from the results obtained from Langmuir adsorption isotherm that the mechanism of corrosion inhibition is occurring mainly through adsorption process.

(4) Surface morphological studies such as FTIR and SEM analysis showed that a film of inhibitor is formed on the electrode surface.

\section{Acknowledgment}

One of the authors, Sumit Kumar, gratefully acknowledges Council for Scientific and Industrial Research (CSIR), New Delhi India, for research fellowship.

\section{References}

[1] I. Ahamad and M. A. Quraishi, "Bis (benzimidazol-2-yl) disulphide: an efficient water soluble inhibitor for corrosion of mild steel in acid media," Corrosion Science, vol. 51, no. 9, pp. 20062013, 2009.

[2] Q. B. Zhang and Y. X. Hua, "Corrosion inhibition of mild steel by alkylimidazolium ionic liquids in hydrochloric acid," Electrochimica Acta, vol. 54, no. 6, pp. 1881-1887, 2009.

[3] W. Li, Q. He, C. Pei, and B. Hou, "Experimental and theoretical investigation of the adsorption behaviour of new triazole derivatives as inhibitors for mild steel corrosion in acid media," Electrochimica Acta, vol. 52, no. 22, pp. 6386-6394, 2007.

[4] R. Solmaz, G. Kardas, B. Yazıc1, and M. Erbil, "Inhibition effect of rhodanine for corrosion of mild steel in hydrochloric acid solution," Protection of Metals, vol. 41, no. 6, pp. 581-585, 2005.

[5] G. Kardas, "The inhibition effect of 2-thiobarbituric acid on the corrosion performance of mild steel in $\mathrm{HCl}$ solution," FizikoKhimicheskaya Mekhanika Materialov, vol. 41, no. 3, pp. 337343, 2005.

[6] M. Yadav, D. Behera, and U. Sharma, "Development of corrosion inhibitors used in acidization of petroleum oil well," Der Chemica Sinica, vol. 3, pp. 262-268, 2012.

[7] M. Yadav, D. Behera, and U. Sharma, "Nontoxic corrosion inhibitors for N80 steel in hydrochloric acid," Arabian Journal of Chemistry, 2012.

[8] M. A. Amin, S. S. Abd El-Rehim, E. E. F. El-Sherbini, and R. S. Bayoumi, "The inhibition of low carbon steel corrosion in hydrochloric acid solutions by succinic acid. Part I. Weight loss, polarization, EIS, PZC, EDX and SEM studies," Electrochimica Acta, vol. 52, no. 11, pp. 3588-3600, 2007.

[9] S. T. Selvi, V. Raman, and N. Rajendran, "Corrosion inhibition of mild steel by benzotriazole derivatives in acidic medium," Journal of Applied Electrochemistry, vol. 33, no. 12, pp. 1175-1182, 2003.

[10] F. Bentiss, M. Lebrini, H. Vezin, and M. Lagrenée, "Experimental and theoretical study of 3-pyridyl-substituted 1,2,4thiadiazole and 1,3,4-thiadiazole as corrosion inhibitors of mild steel in acidic media," Materials Chemistry and Physics, vol. 87, no. 1, pp. 18-23, 2004.

[11] S. K. Shukla and E. E. Ebenso, "Effect of condensation product of thiosemicarbazide and phenyl isothiocynate on corrosion of 
mild steel in sulphuric acid medium," International Journal of Electrochemcal Science, vol. 7, pp. 12134-12145, 2012.

[12] I. A. Ammar and S. Darwish, "Effect of some ions on inhibition of the acid corrosion of fe by thiourea," Corrosion Science, vol. 7, no. 9, pp. 579-596, 1967.

[13] D. D. N. Singh, M. M. Singh, R. S. Chaudhary, and C. V. Agarwal, "Inhibitive effects of isatin, thiosemicarbazide and isatin-3-(3-thiosemicarbazone) on the corrosion of aluminium alloys in nitric acid," Journal of Applied Electrochemistry, vol. 10, no. 5, pp. 587-592, 1980.

[14] G. Trabanelli, G. Brunoro, C. Monticells, and M. Foganolo, in Proceedings of the 9th ICMC, Toronto, Canada, June 1984.

[15] G. D. M. Z. Zhon, R. Tong, and T. Notoxa, Bulletin of the Electrochemical Society, vol. 7, p. 60, 1991.

[16] R. M. Souto, V. Fox, M. M. Laz, M. Pérez, and R. S. González, "Some experiments regarding the corrosion inhibition of copper by benzotriazole and potassium ethyl xanthate," Journal of Electroanalytical Chemistry, vol. 411, no. 1-2, pp. 161-165, 1996.

[17] E. Otero and J. M. Bastidas, "Cleaning of two hundred year-old copper works of art using citric acid with and without benzotriazole and 2-amino-5-mercapto-1,3,4-thiadiazole," Materials and Corrosion, vol. 47, no. 3, pp. 133-138, 1996.

[18] S. S. Mahmoud and E. G. A. Malidy, Egyptian Journal of Chemistry, vol. 39, p. 365, 1996.

[19] O. O. Xometl, N. V. Likhanova, N. Nava et al., "Thiadiazoles as corrosion inhibitors for carbon steel in $\mathrm{H}_{2} \mathrm{SO}_{4}$ solutions," International Journal of Electrochemcal Science, vol. 8, pp. 735752, 2013.

[20] X. J. Raj and N. Rajendran, "Corrosion inhibition effect of substituted thiadiazoles on brass," International Journal of Electrochemical Science, vol. 6, no. 2, pp. 348-366, 2011.

[21] A. Shafiee, E. Naimi, P. Mansobi, A. Foroumadi, and M. Shekari, "Syntheses of substituted-oxazolo-1,3,4-thiadiazoles, 1,3,4-oxadiazoles, and 1,2,4-triazoles," Journal of Heterocyclic Chemistry, vol. 32, no. 4, pp. 1235-1239, 1995.

[22] N. A. Negm, A. A. Hafiz, and M. Y. El Awady, "Influence of structure of the cationic polytriethanolammonium bromide derivatives. II. Corrosion inhibition," Egyptian Journal of Chemistry, vol. 48, no. 2, pp. 201-210, 2005.

[23] A. U. Ezeoke, O. G. Adeyemi, O. A. Akerele, and N. O. Obi-Egbedi, "Computational and experimental studies of 4Aminoantipyrine as corrosion inhibitor for mild steel in sulphuric acid solution," International Journal of Electrochemical Science, vol. 7, no. 1, pp. 534-553, 2012.

[24] E. E. Ebenso and I. B. Obot, "Inhibitive properties, thermodynamic characterization and quantum chemical studies of secnidazole on mild steel corrosion in acidic medium," International Journal of Electrochemical Science, vol. 5, no. 12, pp. 2012-2035, 2010.

[25] K. Jüttner, "Electrochemical impedance spectroscopy (EIS) of corrosion processes on inhomogeneous surfaces," Electrochimica Acta, vol. 35, no. 10, pp. 1501-1508, 1990.

[26] I. Dehri and M. Özcan, "The effect of temperature on the corrosion of mild steel in acidic media in the presence of some sulphur-containing organic compounds," Materials Chemistry and Physics, vol. 98, no. 2-3, pp. 316-323, 2006.

[27] G. Moretti, G. Quartarone, A. Tassan, and A. Zingales, "Pitting corrosion behavior of superferritic stainless steel in waters containing chloride," Werkstoffe und Korrosion, vol. 44, no. 1, pp. 24-30, 1993.
[28] V. R. Saliyan and A. V. Adhikari, "Inhibition of corrosion of mild steel in acid media by N'-benzylidene-3- (quinolin-4ylthio)propanohydrazide," Bulletin of Materials Science, vol. 31, no. 4, pp. 699-711, 2008.

[29] D. Jayaperumal, "Effects of alcohol-based inhibitors on corrosion of mild steel in hydrochloric acid," Materials Chemistry and Physics, vol. 119, no. 3, pp. 478-484, 2010.

[30] W. H. Li, Q. He, S. T. Zhang, C. L. Pei, and B. R. Hou, "Some new triazole derivatives as inhibitors for mild steel corrosion in acidic medium," Journal of Applied Electrochemistry, vol. 38, no. 3, pp. 289-295, 2008.

[31] M. S. Morad, "An electrochemical study on the inhibiting action of some organic phosphonium compounds on the corrosion of mild steel in aerated acid solutions," Corrosion Science, vol. 42, no. 8 , pp. 1307-1326, 2000.

[32] G. Gunasekaran and L. R. Chauhan, "Eco friendly inhibitor for corrosion inhibition of mild steel in phosphoric acid medium," Electrochimica Acta, vol. 49, no. 25, pp. 4387-4395, 2004.

[33] A. Alagta, I. Felhösi, J. Telegdi, I. Bertóti, and E. Kálmán, "Effect of metal ions on corrosion inhibition of pimeloyl-1,5-dihydroxamic acid for steel in neutral solution," Corrosion Science, vol. 49, no. 6, pp. 2754-2766, 2007.

[34] R. Solmaz, "Investigation of the inhibition effect of 5-((E)-4phenylbuta-1,3-dienylideneamino)-1,3,4-thiadiazole-2-thiol Schiff base on mild steel corrosion in hydrochloric acid," Corrosion Science, vol. 52, no. 10, pp. 3321-3330, 2010.

[35] I. Ahamad, R. Prasad, and M. A. Quraishi, "Adsorption and inhibitive properties of some new Mannich bases of Isatin derivatives on corrosion of mild steel in acidic media," Corrosion Science, vol. 52, no. 4, pp. 1472-1481, 2010.

[36] B. Trachli, M. Keddam, H. Takenouti, and A. Srhiri, "Protective effect of electropolymerized 3-amino 1,2,4-triazole towards corrosion of copper in $0.5 \mathrm{M} \mathrm{NaCl}$," Corrosion Science, vol. 44, no. 5, pp. 997-1008, 2002.

[37] J. D. Talati and D. K. Gandhi, "N-heterocyclic compounds as corrosion inhibitors for aluminium-copper alloy in hydrochloric acid," Corrosion Science, vol. 23, no. 12, pp. 1315-1332, 1983.

[38] Z. Szklarska-Smialowska and J. Mankowski, "Crevice corrosion of stainless steels in sodium chloride solution," Corrosion Science, vol. 18, no. 11, pp. 953-960, 1978.

[39] A. Yurt, S. Ulutas, and H. Dal, "Electrochemical and theoretical investigation on the corrosion of aluminium in acidic solution containing some Schiff bases," Applied Surface Science, vol. 253, no. 2, pp. 919-925, 2006. 